\title{
AVALIAÇÃO "IN VITRO" DA MENSURAÇÃO DO COMPRIMENTO DE DENTES COM CINCO MODELOS DE LOCALIZADORES APICAIS ELETRÔNICOS
}

\section{ADELMO JOSÉ CLASEN}

Dissertação apresentada à Faculdade de Odontologia de Bauru, da Universidade de São Paulo, como parte dos requisitos para obtenção do grau de Mestre em Odontologia, área de Endodontia.

(Edição Revisada)

\section{BAURU}

2003 


\section{Clasen, Adelmo José}

C565a Avaliação "in vitro" da mensuração do comprimento de dentes com cinco modelos de localizadores apicais eletrônicos/ Adelmo José Clasen. -- Bauru, 2003.

xxiii, 100 p. : il. ; 29,7 cm.

Dissertação (Mestrado) -- Faculdade de Odontologia de Bauru. Universidade de São Paulo.

Orientador: Prof. Dr. Clovis Monteiro Bramante

Autorizo, exclusivamente para fins acadêmicos e científicos, a reprodução total ou parcial desta dissertação/tese, por processos fotocopiadores e outros meios eletrônicos.

Assinatura:

Data:

Comitê de Ética da FOB: Projeto de pesquisa aprovado em 13 de dezembro de 2002

No do Protocolo: 097/2002

Data: 14 de agosto de 2002 


\section{AVALIAÇÃO "IN VITRO" DA MENSURAÇÃO DO COMPRIMENTO DE DENTES COM CINCO MODELOS DE LOCALIZADORES APICAIS ELETRÔNICOS}

\section{ADELMO JOSÉ CLASEN}

Dissertação apresentada à Faculdade de Odontologia de Bauru, da Universidade de São Paulo, como parte dos requisitos para obtenção do grau de Mestre em Odontologia, área de Endodontia.

Orientador: Prof. Dr. Clovis Monteiro Bramante

(Edição revisada)

\section{BAURU}




\section{ADELMO JOSÉ CLASEN}

07 de Fevereiro de 1958

Alto Paraná - Paraná

1976-1980

1984-1985

Associações
Nascimento

Curso de Graduação em Odontologia na Universidade Estadual de Londrina

Curso de Especialização em Endodontia, na Faculdade de Odontologia de Marília

Conselho Regional de Odontologia do Estado do Paraná, CRO PR

Associação Brasileira de Odontologia Regional de Toledo-Pr 
Dedicatória 


\section{DEDICATÓRIA}

Dedico este trabalho à minha esposa Elisabete e às minhas filhas, Camila e Daniele que se privaram da minha companhia por muitas horas, e que sempre estiveram presentes quando precisei. 
Agradecimentos 


\section{AGRADECIMENTOS}

Ao Grande Arquiteto do Universo em primeiro lugar, porque sem Ele nada somos.

Aos meus pais, que sempre me incentivaram e apoiaram nos meus estudos.

A Zuleica e Horácio Ceribelli, que com carinho me receberam em sua casa durante todo

o Mestrado.

Ao Prof. Dr. Kaneo Okano, que com a sua sabedoria oriental, sempre teve uma palavra de incentivo e apoio, no qual me inspirei a me aprofundar nos estudos da Endodontia e com o qual tive as primeiras noções como seu aluno na Graduação.

A Dra Alice Ogawa, que me propiciou um primeiro contato mais especifico com a Endodontia, me incentivando a fazer o curso de especialização.

Ao Prof. Mauro Celso Boer, amigo e colega de Graduação, que durante meus estudos de Mestrado sempre se colocou à disposição para me ajudar e incentivar-me nos

estudos.

Ao Prof. Dr. Carlos Alberto Spironelli Ramos, que sempre se mostrou solicito quando a ele recorri e da qual pude realizar meu trabalho inspirado nos seus trabalhos de Mestrado e Doutorado. 
Ao Prof. Dr. Ivaldo Gomes de Moraes, no qual encontrei um grande amigo, que com sua sabedoria sempre tem uma palavra amiga e de incentivo.

Ao Prof. Dr. Norberti Bernardineli, que sempre esteve pronto a dirimir qualquer dúvida que fosse apresentada, mostrando um espírito de orientação e de amizade.

Ao Prof. Dr. Roberto Brandão Garcia, que com sua calma e tranqüilidade sempre me transmitiu muita paz, para poder bem desenvolver este trabalho.

A Prof ${ }^{a}$ Dra $^{\mathrm{a}}$ Maria Fidela de Lima Navarro que sempre esteve presente nos momentos de maiores dificuldades deste Mestrado, sempre tendo uma palavra de incentivo.

Ao Prof. Dr. Newton de Moraes que sempre mostrou o quanto importante era este mestrado, e sempre estimulou a cumprir todas as metas.

Ao Prof. Dr. Lauris na realização da estatística.

Ao Prof. Dr. Sérgio do Departamento de Microbiologia, pelo auxílio na confecção do ágar para a realização deste experimento.

Aos colegas de Mestrado, Aline, Alfredo, Bruno, Dirce, Daniela, Osni, Flávia, Mioto, Roberto. 
Aos funcionários do Departamento de Endodontia, Edimauro, Sueli, Neide e Patrícia que sempre quando a eles recorri se mostraram solícitos.

Ao Ricardo, que muito me auxiliou com os seus conhecimentos de computação.

Aos amigos Edson e Dyogo que me auxiliaram nos mistérios da computação.

Aos colegas Marcos Cirino, Antonio Francisco Grando, Clóvis Takahaschi e Denise Davidoff, que sempre estiveram juntos nesta caminhada. 
Agradecimento Especial 


\section{AGRADECIMENTO ESPECIAL}

Ao meu orientador, Prof. Dr. Clovis Monteiro Bramante, que com muita paciência, dedicação, cortesia e amizade me conduziu em todos os momentos deste trabalho. 


\section{SUMÁRIO}

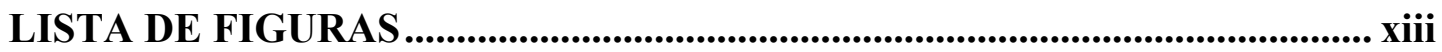

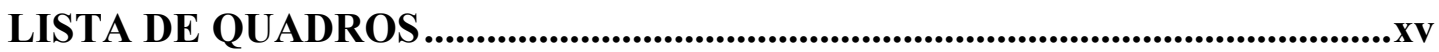

LISTA DE TABELAS E GRÁFICOS ................................................................ xvii

LISTA DE ABREVIATURAS E SÍMBOLOS ........................................................xix

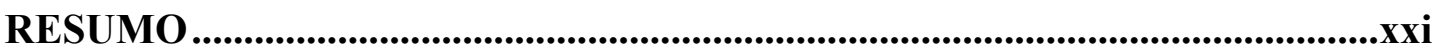

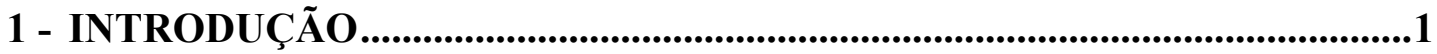

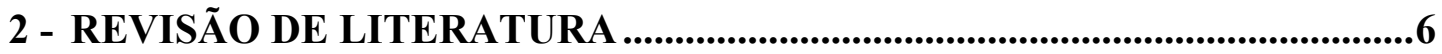

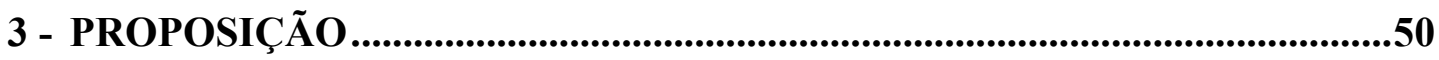

4 - MATERIAL E MÉTODOS .......................................................................52

4.1 - SELEÇÃO E PREPAROS DOS DENTES ...............................................53

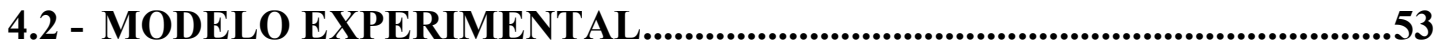

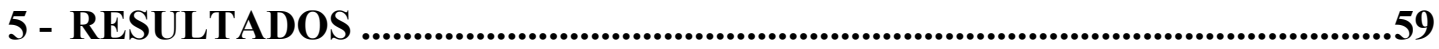

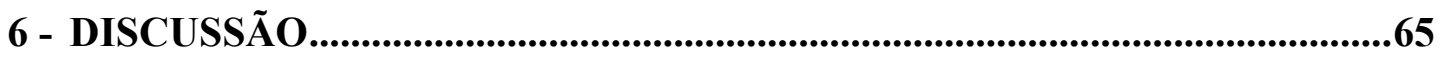

6.1 - DISCUSSÃO DA METODOLOGIA .......................................................66

6.2 - DISCUSSÃO DOS RESULTADOS ...............................................................74

6.3 - CONSIDERAÇÕES FINAIS ........................................................................

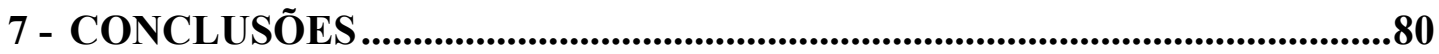


REFERÊNCIAS BIBLIOGRÁFICAS..................................................................882

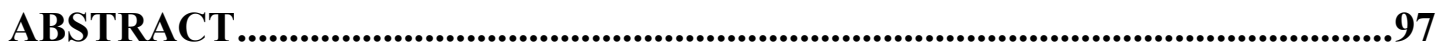

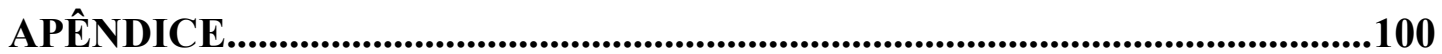


Lista de Figuras 


\section{LISTA DE FIGURAS}

FIGURA 1 - Representação esquemática do ápice radicular.

FIGURA 2 - Posição dos dentes na cuba de vidro com a solução de ágar a 1\% .....54

FIGURA 3 - Modo de realizar a leitura com os localizadores apicais eletrônicos 55

FIGURA 4 - Aparelhos eletrônicos localizadores apicais utilizados no experimento 56 
Lista de Quadros 


\section{LISTA DE QUADROS}

QUADRO 1 - Localizadores apicais eletrônicos e seus fabricantes

QUADRO 2 - Valores individuais (em mm) para todas as medidas executadas. $\mathrm{Na}$ última coluna, o local da saída do forame apical. .61

QUADRO 3 - Resultados (em mm) de cada aparelho, já descontando 0,5 mm do comprimento real do dente, considerando a lima introduzida no canal .62 
Lista de Tabelas e Gráficos 


\section{LISTA DE TABELAS E GRÁFICOS}

TABELA 1 - Análise de variância a um critério, aplicado aos valores dos quadros 2 e 3 .62

TABELA 2 - Teste de Tukey, para confrontação entre os aparelhos, (as linhas verticais abrangem os aparelhos em que a diferença não foi estatisticamente significante)

TABELA 3 - Valores de acerto e erros (número de dentes e porcentagens), considerando o aparelho utilizado .63

GRÁFICO 1 - Porcentagem de acertos e erros para cada aparelho .64 
Lista de Abreviaturas e Símbolos 


\section{LISTA DE ABREVIATURAS E SÍMBOLOS}

A

EDTA

G

$\mathrm{H}_{2} \mathrm{O}$

$\mathrm{H}_{2} \mathrm{O}_{2}$

$\mathrm{KH}_{2} \mathrm{PO}_{4}$

$\Omega$

$\mathbf{K} \Omega$

$\boldsymbol{\mu A}$

MI

$\mathbf{m m}$

$\mathrm{NaCl}$

$\mathrm{Na}_{2} \mathrm{HPO}_{4}$

NaOCl

$\mathbf{n}^{\mathbf{0}}$

$\%$

Rc prep

Rpm
Ampéres (medida de corrente elétrica)

Ácido dietil-tetra-acético

Grama

Água

Água Oxigenada

Fosfato ácido de potássio

$\mathrm{Ohm}$

Kilo Ohms

Micro-ampéres

Mililitros

milímetros

Cloreto de sódio

Fosfato ácido de sódio

Hipoclorito de sódio

Número

Porcento

EDTA em veículo cremoso

Rotação por minuto 
Resumo 


\section{RESUMO}

A determinação do limite apical de instrumentação é um requisito de suma importância para se obter êxito no tratamento endodôntico. Os métodos mais usados para este fim são os radiográficos, porém os métodos eletrônicos tem tido uma grande popularidade entre Endodontistas e Clínicos Gerais, conseqüentemente, muitas marcas de localizadores apicais eletrônicos foram desenvolvidas e se encontram presentes no mercado.

Este estudo foi realizado com o intuito de fazer uma comparação "in vitro" da mensuração do comprimento dos dentes entre os localizadores apicais eletrônicos ROOT ZX, JUSTY II, BINGO 1020, APIT 5 e FORAMATRON IV.

Foram utilizados 30 incisivos superiores extraídos de humanos, que após a abertura coronária foram medidos de dois modos. Uma lima foi inserida no canal até que sua ponta aparecesse no forame apical, a qual era então removida e medida. Outro modo foi o de medir o comprimento do dente desde o bordo incisal até o ápice com o auxilio de um paquímetro. Os dentes foram então montados em um meio ágar salino tamponado a $1 \%$.

As medidas eletrônicas foram obtidas com os aparelhos em teste quando no mostrador estivesse marcando 0,5 para o ROOT ZX, BINGO 1020 e FORAMATRON IV, para o JUSTY II quando no mostrador o ponteiro estivesse no meio da faixa amarela entre o 1 e o apex, e no APIT 5 quando o ponteiro estivesse na 
faixa verde entre o 1 e o apex. Essas medidas foram então comparadas com aquelas anteriormente obtidas.

O ROOT ZX e BINGO 1020 foram eficientes em 100\% dos casos, o JUSTY II em 96,67\% e o APIT 5 em 76,67\% .

O FORAMATRON IV apresentou índice de acerto de apenas 43,33\%, com diferença estatisticamente significante entre os demais aparelhos. 
1 - Introdução 


\section{1 - INTRODUÇÃO}

$\mathrm{Na}$ Endodontia, já há muito tempo, os procedimentos relacionados a tratamento de canais radiculares são: abertura, limpeza e vedação destes canais. Para que estes procedimentos estejam corretos, faz-se necessário a obtenção exata do comprimento de trabalho, pois somente realizando uma odontometria precisa obtém-se segundo CERTOSIMO ${ }^{18}$ a "tríade do sucesso endodôntico", através da desinfecção microbiana, preparo do canal ideal e selamento hermético.

Existem três pontos importantes no ápice de um dente que necessitam ser familiar, para que o comprimento ideal de trabalho seja determinado. 1) O ápice anatômico ou radiográfico, que é definido como o final anatômico da raiz quando visto na radiografia. 2) O forame apical (diâmetro maior), que é a região onde o canal deixa a superfície próxima ao ligamento periodontal. 3) A constrição apical (diâmetro menor), que é a área do canal que têm o diâmetro mais estreito.(FIGURA 1).

O limite ideal para a realização do preparo biomecânico é aquele onde se encontra a constrição apical, que normalmente está localizado de 0,5 a $0,7 \mathrm{~mm}$ aquém do ápice anatômico. Porém, segundo $\mathrm{KUTTLER}^{57}$, ocorre uma grande variação na anatomia apical e muitas vezes há um desvio do vértice central da raiz, dificultando a realização da odontometria.

Para realização da odontometria, já foram propostos diversos métodos. Estes métodos compreendem o senso táctil-digital, tomadas radiográficas, tomadas 
radiográficas que são interpretadas através de fórmulas matemáticas, gabaritos, escalas e métodos eletrônicos.

O método de sensibilidade táctil-digital é muito incerto. Tradicionalmente o método radiográfico tem sido o mais utilizado na determinação do comprimento de trabalho, apesar de muitas limitações técnicas estarem associadas a este método. Tomadas radiográficas expõe o paciente à radiação ionizante e mostram uma imagem bidimensional de uma estrutura tridimensional. Na tentativa de superar as limitações radio-ópticas do método radiográfico na obtenção da odontometria, muitos aparelhos foram desenvolvidos com princípios de diferencial na passagem de corrente elétrica entre a estrutura dental e o ligamento periodontal, a fim de estabelecer o comprimento dos canais radiculares.

O desenvolvimento destes aparelhos teve início em 1942 com SUZUKI $^{100}$, que realizou um trabalho em cães e descobriu, que, a resistência elétrica entre o ligamento periodontal e a mucosa oral apresentava um valor constante de 6,5 $\mathrm{K} \Omega$. Baseado neste princípio, $\mathrm{SUNADA}^{99}$ em 1962, desenvolveu o método eletrônico para a localização do forame apical.

Todos os localizadores de ápice funcionam usando o corpo humano como um componente para completar o circuito elétrico. Um lado do circuito do localizador de ápice fica conectado a um instrumento endodôntico, e o outro lado, fica conectado a um grampo que é apoiado no lábio do paciente.

No processo de evolução dos aparelhos eletrônicos, pode-se classificálos basicamente em três tipos: tipo resistência, tipo impedância e tipo freqüência dependente, (McDONALD ${ }^{66}$ 1992). 
Os aparelhos do tipo resistência são baseados no princípio de SUNADA $^{99}$, com o registro de que a resistência elétrica entre o ligamento periodontal e a mucosa oral apresentam um valor constante. O tecido pulpar e a umidade no interior do canal devem ser removidos antes de realizar a medida. Estes aparelhos são chamados de localizadores apicais de primeira geração.

Os aparelhos do tipo impedância, também chamados de segunda geração, tem a vantagem de poder operar com umidade no interior do canal, porém requerem um aprendizado complexo para interpretar a medida, além do que empregam uma corrente elétrica maior que os aparelhos do tipo freqüência, podendo causar desconforto para o paciente e ainda necessitam de isolamento especial da lima, exceto na sua ponta (McDONALD; HOVLAND ${ }^{67}$ 1990).

Os aparelhos do tipo freqüência dependente ou de terceira geração funcionam sob o princípio de que existe uma diferença de impedância entre os eletrodos. O deslocamento apical do instrumento endodôntico proporciona a medição da diferença de impedância (McDONALD ${ }^{66}$ 1992).

Muitos trabalhos científicos já foram realizados visando estudar os diferentes tipos de aparelhos eletrônicos existentes no mercado.

O objetivo deste estudo é fazer uma comparação entre a precisão na determinação do comprimento do dente, utilizando cinco modelos de localizadores apicais disponíveis no mercado (JUSTY II, ROOT ZX, BINGO 1020, APIT 5 e FORAMATRON IV). 


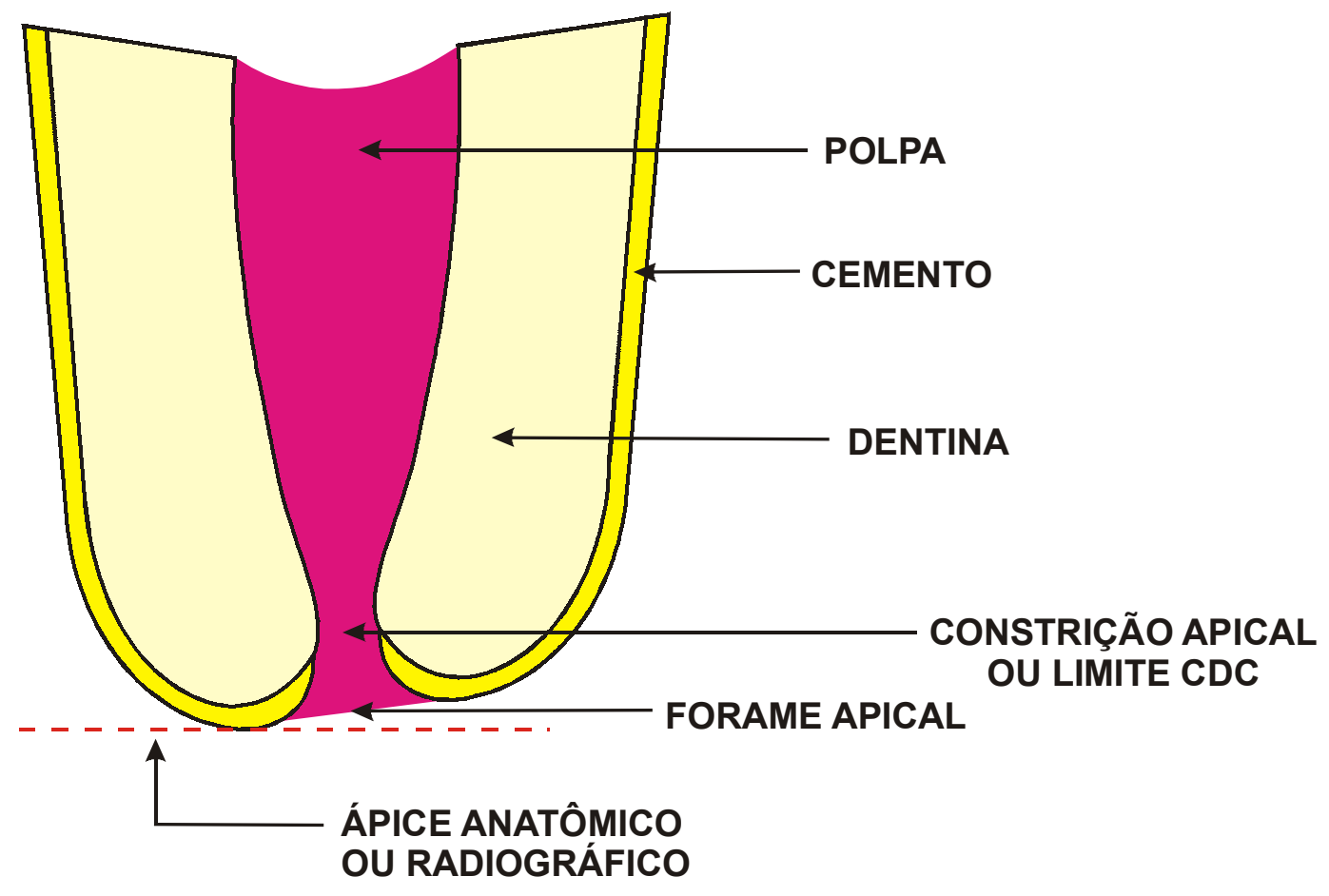

FIGURA 1 - REPRESENTAÇÃO ESQUEMÁTICA DO ÁPICE RADICULAR 
2 - Revisão de Literatura 


\section{2 - REVISÃO DE LITERATURA}

$\mathrm{Na}$ Endodontia os pesquisadores são unânimes em afirmar que é de suma importância estabelecer o real comprimento de trabalho quando da realização de um tratamento endodôntico. Para se chegar a este comprimento várias técnicas já foram pesquisadas e estudadas, desde sensibilidade táctil, radiografias e aparelhos eletrônicos. Há muito tempo os estudiosos pesquisam sobre as técnicas eletrônicas, e os resultados são muito variáveis com relação à técnica ideal e qual o melhor aparelho a ser utilizado.

Os primeiros passos com relação ao método eletrônico para obtenção do comprimento do canal radicular foram dados por CUSTER ${ }^{24}$, em 1918, que se mostrou preocupado com o grande número de extrações dentárias indicadas pelos médicos, que associavam os dentes à quase todas as doenças humanas. Como os dentes despolpados eram freqüentemente indicados de serem as causas de distúrbios sistêmicos, necessário era desenvolver técnicas que realizassem a medida exata do canal radicular, pois o problema estaria relacionado ao forame apical que necessitava ser selado e descontaminado. Objetivando a localização exata do forame apical o autor relata dois métodos para este fim, sendo um radiográfico e outro elétrico, este baseado na diferença da condutividade elétrica de um canal pulpar seco ou preenchido com líquido sem condução e a condutividade dos tecidos logo além do forame apical. O autor desenvolveu um aparelho que consistia de um miliamperímetro que era ligado a uma fonte de corrente contínua e dois eletrodos, um eletrodo negativo que seria colocado próximo ao dente a ser medido e o outro positivo em forma de fio de aço que seria colocado no interior do canal radicular. Quando esses eletrodos estavam 
conectados, a lima era introduzida no canal para, ao passar o forame apical e fechar o circuito, determinar no mostrador do aparelho este momento.

SUZUKI $^{100}$, em 1942 realizando um estudo em cães, verificou que a resistência elétrica obtida entre a mucosa oral e um eletrodo acoplado a um instrumento inserido no interior do canal radicular era constante.

Tomando como referências os achados de SUZUKI ${ }^{100}$, SUNADA ${ }^{99}$, em 1962, propôs um método para determinação do comprimento de trabalho sem a utilização de radiografias. Utilizou para isto de um ohmímetro e verificou em 124 dentes que a resistência à passagem de corrente elétrica pela membrana periodontal era constante e igual a $6,5 \mathrm{~K} \Omega(40 \mu \mathrm{A})$, sendo coincidente com a mucosa oral. Constatou ainda que era possível determinar o comprimento real do canal quando o amperímetro registrava $40 \mu \mathrm{A}$. Baseado neste valor, o autor sugeriu a teoria de que a resistência elétrica entre a mucosa e o ligamento periodontal possui uma relação constante, independente do sexo, idade ou tipo de dente. A partir de então, aparelhos eletrônicos utilizando esse princípio, têm sido desenvolvidos e sua eficiência avaliada por diversas metodologias.

INOUE $^{51}$ em 1973 realizou um experimento em 101 canais radiculares de 72 pacientes, avaliando a precisão do SONO-EXPLORER, com o propósito de examinar o som emitido a partir da passagem de corrente elétrica de baixa freqüência do sulco gengival, da membrana da mucosa oral e do periodonto do forame apical. O autor observou que o som produzido pela penetração da lima na região apical do canal radicular (em contato com o periodonto) era idêntico ao produzido no sulco gengival independente da idade, sexo do paciente ou tipo de dente e também, que 
quando a ponta da lima estava de 0,5 a 1,0 $\mathrm{mm}$ do ápice do dente o som era de dez decibéis abaixo do que aquele produzido no sulco gengival.

Com o objetivo de determinar a localização do forame apical, O’NEILL $^{74}$ em 1974, avaliou clinicamente a acuidade do SONO-EXPLORER em 53 canais radiculares. As leituras obtidas pelo aparelho foram comparadas com a análise do local do forame após a extração dos dentes. Em $83 \%$ dos casos as medidas foram idênticas, e a medida elétrica foi $0,5 \mathrm{~mm}$ mais curta que a real em $17 \%$ dos casos. $\mathrm{O}$ autor também observou, que canais preenchidos com hipoclorito de sódio tenderam a dar falsas leituras e que quando estes canais foram secos com cones de papel, novamente se obteve leituras mais precisas. Conclui o autor, que quando apropriadamente usado este aparelho parece ser um instrumento confiável em localizar o forame apical de canais radiculares.

BRAMANTE; BERBERT ${ }^{11}$, em 1974, comparam os métodos de odontometria de BEST ${ }^{9}, \mathrm{SUNADA}^{99}, \mathrm{BREGMAN}^{12}, \mathrm{INGLE}^{50}$ e BRAMANTE${ }^{11}$, com o objetivo de verificar a precisão dos resultados obtidos em condições clínicas, com aquelas obtidas “in vitro", após a extração dos dentes. Foram utilizados neste experimento 224 dentes com indicações de extração por razões protéticas ou ortodônticas, de 46 pacientes de ambos os sexos. Os dentes foram medidos "in vivo" pelos vários métodos, e os comprimentos reais determinados após a extração do mesmo. Após realização da análise estatística os autores chegaram as seguintes conclusões:

1- O método de INGLE ${ }^{50}$ apresentou maior porcentagem de medições de sucesso. 
2- Método de $\operatorname{BEST}^{9}$ e de BREGMAN ${ }^{12}$ apresentaram uma pequena porcentagem de medição de sucesso.

3- O método de SUNADA ${ }^{99}$ apresentou melhores resultados para as raízes palatinas de pré-molares e molares superiores.

4- Com o método de BRAMANTE ${ }^{11}$ foi possível melhorar os resultados dos métodos de BREGMAN ${ }^{12}$ e INGLE ${ }^{50}$.

SEIDBERG et al. ${ }^{92}$, em 1975 realizaram uma investigação clínica para medir o comprimento de trabalho de canais radiculares com aparelho eletrônico e com o método de sensação táctil digital. Utilizando-se do SONO-EXPLORER “in vivo", determinaram a medida de comprimento de trabalho em 50 dentes, e outros 50 foram medidos pelo método de sensibilidade táctil. $\mathrm{O}$ método radiográfico foi utilizado para checar a posição da lima no ápice do dente. Avaliando os resultados, o método da sensibilidade táctil digital apresentou uma precisão de 64\% na localização do forame apical, contra 48\% quando utilizado o aparelho eletrônico. Os autores chegaram a conclusão, que o SONO-EXPLORER é menos confiável para determinar o comprimento de trabalho do que o método de sensibilidade táctil digital.

BLANK; TENCA; PELLEU ${ }^{10}$, em 1975 avaliaram clinicamente os aparelhos ENDOMETER e o SONO-EXPLORER quando usados para localização do forame apical e determinação do comprimento do canal radicular. Foram utilizados neste estudo 65 dentes com 103 canais radiculares. Ambos os aparelhos trabalharam dentro dos limites aceitáveis, ENDOMETER (85\%), SONO-EXPLORER (89\%) dos canais testados. Apesar de não ter havido diferença estatística entre os aparelhos, as 
leituras foram mais consistentes com o ENDOMETER e, clinicamente, também foi menos complicado para o uso.

Com o objetivo de avaliar a precisão do SONO-EXPLORER, na determinação do comprimento do canal radicular, BUSCH et al. ${ }^{17}$, em 1976, realizaram 193 medições de dentes uniradiculados em 72 pacientes utilizando este aparelho. Quando obtido o comprimento de trabalho através da medição sonar, a lima era presa por uma pinça hemostática e após, os valores em milímetros eram anotados. Em seguida esta lima era novamente introduzida no canal e uma radiografia era realizada de maneira usual. Os resultados obtidos foram de $93,3 \%$ dos casos dentro de uma faixa de mais ou menos $0,5 \mathrm{~mm}$ do ápice radiográfico. Os autores também puderam observar que o aparelho apresentou-se melhor nos casos vitais em relação aos casos de necrose.

PLANT; NEWMAN ${ }^{81}$, em 1976, fizeram uma avaliação clínica do SONO-EXPLORER. Foram medidos 32 canais radiculares que estavam indicados para extração por motivos diversos. Após a extração as medições diretas foram feitas e comparadas com as obtidas pelos meios eletrônicos. Em somente dois casos houve diferença entre as medições eletrônicas e a medida do comprimento real do canal. Nestes dois casos as medidas estavam aquém das medições diretas de 0,3 a 0,5 mm. Os autores chegaram a conclusão que o SONO-EXPLORER é útil para ser usado em procedimentos endodônticos.

Em 1977, SUCHDE; TALIM ${ }^{98}$, desenvolveram um novo aparelho para determinação do comprimento de trabalho e denominaram de ELECTRONIC OHMMETER, sendo que a diferença em relação aos existentes no mercado estava no funcionamento com corrente alternada ao invés de corrente contínua, sendo esta 
modulada em 5 microamperes. Para testar o aparelho foram utilizados dentes anteriores e posteriores indicados para tratamento endodôntico, sendo 51 dentes anteriores superiores de quarenta e três pacientes e 25 canais radiculares de dentes posteriores de dez pacientes. Após a realização do isolamento absoluto foi feita a abertura coronária e o canal foi biomecanicamente preparado, irrigado com peróxido de hidrogênio e água destilada e secado com cones de papel. Após o canal estar totalmente seco, o ELECTRONIC OHMMETER, foi ligado. Um eletrodo foi colocado na comissura labial e um cone de prata foi introduzido no canal até que o valor médio previamente calculado fosse obtido no medidor, um cursor foi ajustado na superfície incisal ou oclusal. Em seguida, foi realizada uma tomada radiográfica, para verificar a relação entre o cone de prata e o ápice. O instrumento foi retirado e em seguida realizada a medida. Aceitou-se como precisa, a medida, quando o cone foi até o ápice ou a $0,5 \mathrm{~mm}$ aquém. Os resultados foram precisos em 45 dentes $(88,2 \%)$ e imprecisos em 6 dentes (11,8\%). A presença de uma lesão no tecido periapical, ápice radicular amplo, e exsudato no canal radicular contribuem para a imprecisão na determinação do comprimento de trabalho.

KAUFMAN; HELING; SECHAIEK ${ }^{53}$ em 1979, utilizando o SONOEXPLORER, realizaram um estudo comparativo para determinação da odontometria entre o método eletrônico e o método radiográfico de INGLE $^{50}$. Para este estudo os autores utilizaram 106 canais radiculares com necessidade de tratamento endodontico de 61 pacientes, com idade variando de 19 a 49 anos. Em 48,3\% dos casos a leitura do SONO-EXPLORER e radiográficos foram idênticas; em 34,4\% a leitura do sistema eletrônico foi mais curta em $0,5 \mathrm{~mm}$ em relação ao ápice radiográfico; nos 17,3\% restantes as leituras foram de 0,5 a 2,0 mm mais curtas. Os autores também concluíram 
que as medidas apresentadas por este aparelho determinam a junção cemento-dentinária, embora às vezes possam parecer curtas nas observações radiográficas.

BECKER et al. $^{6}$, em 1980, realizaram um experimento em dentes decíduos de suínos, com o objetivo de determinar o comprimento do canal radicular, utilizando o FORAMETER. Após a extirpação pulpar, as medidas eletrônicas foram obtidas, e em seguida comparadas com as tomadas radiográficas e medições diretas feitas após a extração destes dentes. Os autores concluíram que o método radiográfico foi mais preciso quando comparado com o eletrônico.

CHUNN; ZARDIACKAS; MENKE ${ }^{21}$, em 1981, avaliaram "in vivo" o FORAMETER, com relação à capacidade deste aparelho em determinar a localização do forame apical entre 0,5 a $1,0 \mathrm{~mm}$. Uma lima acoplada ao aparelho foi colocada no canal radicular até que o mesmo indicasse estar de 0,5 a 1,0 mm aquém do ápice. A lima foi então fixada com resina composta e duas tomadas radiográficas foram executadas, uma com a técnica da bissetriz e a outra do paralelismo antes da extração do dente. As medidas reais do dente foram obtidas através de microscopia, observando-se que $65 \%$ das limas estavam passando a abertura do forame apical. Radiograficamente $55 \%$ das medidas foram consideradas aquém do ápice radicular, no entanto, $45 \%$ das limas, que mediam aquém, estavam na realidade passando a abertura do forame. Portanto o FORAMETER, não se mostrou preciso em $65 \%$ dos casos e a avaliação radiográfica foi imprecisa em $45 \%$.

USHIYAMA $^{104}$, em 1983, apresenta um novo método para localizar a constrição apical e forame "in vivo", desenvolvido a partir de um estudo em que foi preparado um modelo "in vitro", com dente humano extraído. O método descrito 
permite determinar o comprimento de trabalho de um canal preenchido com um eletrólito. Os experimentos foram desenvolvidos com dentes humanos uniradiculados extraídos. Após abertura coronária os dentes foram alargados com limas tipo $\mathrm{K} \mathrm{n}^{\circ} 25$ e mantidos em solução de $\mathrm{NaCl}$ a $0,9 \%$. Uma corrente elétrica de $10 \mu \mathrm{A}$ foi aplicada e as variações do gradiente de voltagem, conforme a ponta do instrumento se aproximava do forame apical foi registrada. Estas variações determinam uma curva de aumento constante até a região apical, ocorrendo uma queda brusca, quando o instrumento ultrapassava a constrição apical (de $14 \mu \mathrm{V}$ para $0,4 \mu \mathrm{V}$ ). Conclui o autor, que a principal vantagem no método descrito, é que a presença de exsudação no tecido, sangue ou pus no canal preenchido com $\mathrm{NaCl}$ a $0,9 \%$ não afetará a leitura por eles terem a mesma condutividade que a solução salina.

Em 1983, NAHMIAS; AURELIO; GERSTEIN ${ }^{72}$, apresentaram três casos clínicos em que foi possível através da mensuração eletrônica, diagnosticar perfuração radicular, devido ao fato que a resistência elétrica entre a membrana da mucosa e o periodonto terem uma relação constante.

Ainda em 1983, os mesmos autores ${ }^{5}$ desenvolveram uma técnica "in vitro" para medir o comprimento do canal eletronicamente. Um dente extraído foi colocado dentro de um tubo de polietileno, que foi preenchido com uma solução de ágar aquecida $\left(2 \mathrm{~g}\right.$ em $100 \mathrm{ml}$ de solução salina tamponada - $\mathrm{NaCl}, 9 \mathrm{~g} ; \mathrm{Na}_{2} \mathrm{HPO}_{4}, 1,43 \mathrm{~g}$; $\left.\mathrm{KH}_{2} \mathrm{PO}_{4}, 0,18 \mathrm{~g} ; \mathrm{H}_{2} \mathrm{O}, 1000 \mathrm{ml}\right)$; este conjunto foi então refrigerado por 2 horas para permitir o ágar solidificar. Uma lima foi introduzida no interior do dente para ser feita à leitura eletrônica e o outro eletrodo, feito com um fio de aço, transpassava a base inferior do tubo de polietileno. 
Um novo aparelho eletrônico (ENDOCATER) foi analisado por RIKUKAWA et al. $^{89}$ em 1983. As medidas obtidas com este aparelho foram comparadas com as radiografias e também com dois outros aparelhos eletrônicos, o ENDODONTIC METER e o ROOT CANAL METER. Na comparação radiográfica o ENDOCATER se portou da seguinte forma: em 43 canais uniradiculados medidos, 10 estavam exatamente no ápice $(23,2 \%)$, um estava além $(2,3 \%)$, e 32 estavam aquém do ápice $(74,4 \%)$. Comparado com os outros aparelhos utilizados o ENDOCATER mostrou-se mais preciso a realizar essas medidas.

BERMAN; FLEISCHMAN ${ }^{8}$, em 1984 avaliaram a eficiência do NEOSONO-D em localizar o forame apical. Neste estudo foram utilizados 24 canais radiculares com raízes totalmente formadas e 5 canais radiculares com raízes que apresentavam ápices incompletos. Uma lima inserida no aparelho foi fixada no interior do canal no momento em que o mostrador do aparelho indicava zero (indicando a localização do ligamento periodontal apical). Antes da exodontia destes dentes foi realizada uma tomada radiográfica. A posição da ponta da lima em relação ao forame apical foi medida diretamente no microscópio, da mesma forma que foi realizada a medida na radiografia entre a ponta da lima e o ápice radiográfico. Microscopicamente a lima ficou aquém do forame apical em $0,5 \mathrm{~mm}$ nos dentes que apresentavam ápices completamente formados, já nos casos em que em que os ápices estavam incompletos a lima ficou a vários milímetros aquém do forame apical. Concluíram os autores que este aparelho é confiável em localizar o forame apical com tolerâncias clínicas aceitáveis.

Avaliando clinicamente um aparelho medidor eletrônico, ABBOTT $^{1}$, em 1987, fez um estudo em 85 canais radiculares e comparou a técnica radiográfica 
com a técnica eletrônica utilizando o ENDO RADAR. Dos canais estudados, 66 $(77,6 \%)$ estavam iguais nas medidas pelos dois métodos. Em 10 canais $(11,8 \%)$ as medidas eletrônicas estavam aquém que as radiográficas; em 7 casos $(8,2 \%)$ as medidas do aparelho estavam além que as obtidas pelo método radiográfico e, em 2 casos $(2,4 \%)$ os dentes apresentavam perfurações laterais e tiveram leitura zero no aparelho. Conclui o autor, que este aparelho possui inúmeras limitações e que como único método para determinar o comprimento de canal não parece ser indicado isoladamente, sendo necessário o uso da técnica radiográfica.

NAHMIAS; AURELIO; GERTEIN ${ }^{71}$, em 1987, utilizando-se de uma metodologia já empregada em 1983, avaliaram os localizadores apicais eletrônicos SONO-EXPLORER, C.L.METER e NEOSONO-D. Os 60 dentes selecionados para este experimento foram divididos em 6 grupos de 10 dentes cada e colocados em um tubo de polietileno contendo ágar a $2 \%$ em solução salina, fazendo com que as raízes dos mesmos ficassem recobertas pela solução. A análise dos resultados demonstrou que os aparelhos foram capazes de localizar o forame apical a uma distância média de 0,223 mm do ápice anatômico, não havendo diferença significante entre o grupo controle e os diferentes aparelhos testados. Concluíram, que o modelo experimental simula o posicionamento clínico e que poderia ser usado para analisar diferentes localizadores de ápices presentes no mercado.

AUN; GAVINI; MOURA ${ }^{3}$, em 1988 valendo-se de um localizador apical audiométrico, o SONO-EXPLORER MARK III, avaliaram clinicamente 50 dentes com polpa mortificada, num total de 60 canais radiculares. Com um instrumento posicionado no interior do canal radicular, no local determinado pelo aparelho, foi feita 
uma tomada radiográfica, avaliando-se após o processamento da película, a distância entre a ponta do instrumento e o vértice radiográfico da raiz. Em 57 canais o aparelho foi eficiente na localização da porção mais estreita do canal radicular, mostrando ser eficiente na determinação do comprimento dos canais radiculares.

Ainda em 1988, AUN et al. $^{4}$, fizeram medições com o ENDOMETER, com a finalidade de determinar o comprimento de canais radiculares de 30 dentes com polpa mortificada e com indicação prévia de extração. Após a obtenção do comprimento dos canais pelo método elétrico, os dentes foram extraídos e tiveram seus canais radiculares mensurados diretamente com o auxílio de um instrumento ajustado ao forame apical. Os valores foram confrontados e verificou-se que $93,34 \%$ das medidas eletrônicas foram coincidentes com a medida do comprimento real dos dentes após extração, não existindo diferença estatística significante.

MORAES et al. $^{68}$, em 1988, verificaram a capacidade do FORAMATRON III em registrar a posição a $0,5 \mathrm{~mm}$ da constrição apical em 21 canais radiculares de 18 dentes indicados para extração. Os resultados foram avaliados com radiografias, e mostrou que $38,1 \%$ das medidas determinadas pelo aparelho eletrônico estavam a $0,5 \mathrm{~mm}$ aquém do forame apical, enquanto que com a técnica radiográfica da bissetriz foram precisas em $61,9 \%$ dos casos. Os autores concluem que a associação do método eletrônico com o radiográfico possa proporcionar melhores resultados que o uso de qualquer um deles separadamente.

HÜLSMANN; PIEPER ${ }^{48}$, em 1989 empregaram o localizador apical eletrônico EXACT-A-PEX em dentes que apresentavam ápices radiculares incompletos e dentes submetidos a apecificação. Os autores constataram que as medidas com ápices 
abertos se mostraram imprecisas. Já, após o fechamento apical ter ocorrido, o localizador apical foi preciso em todos os dentes e as medidas foram coincidentes com as das radiografias.

BRITTO Jr.; BIRAL; VALDRIGHI ${ }^{13}$, em 1989 realizaram um estudo comparativo entre os métodos eletrônico e radiográfico (técnica de $\operatorname{INGLE}^{50}$ ), na realização de odontometria, confrontando com as medidas físicas do dente para avaliar o grau de precisão. Os dentes utilizados foram multiradiculados. Concluíram os autores que ambos os métodos apresentaram um percentual de acerto abaixo de 50\%. O aparelho utilizado foi o PIO e sua tendência foi de fornecer medidas de comprimento dos dentes menores que as reais, já o método radiográfico, de um modo geral, apresentou uma tendência à obtenção de medidas de comprimentos dos dentes maiores que as reais. O percentual de medidas aceitáveis foi maior para o método elétrico $(36,36 \%)$ do que para o método radiográfico $(24,6 \%)$.

FOUAD; KRELL ${ }^{34}$ em 1989 compararam cinco modelos de localizadores apicais eletrônicos, realizando um experimento "in vitro" com dentes naturais. Os aparelhos analisados foram EXACT-A-PEX, ENDOCATER, NEOSONO-D, APEX-FINDER e o SONO-EXPLORER MARK III. Foi utilizado como parâmetro de medida, o comprimento real do canal radicular. Os autores também estudaram a precisão dos aparelhos quanto à determinação do forame apical, utilizando pontas de guta-percha condutiva. Observaram ainda, que a presença de fluídos no interior do canal (etanol, peróxido de hidrogênio, solução salina, xilocaína, hipoclorito de sódio e sangue), alteram as medidas apontadas pelos aparelhos, e recomendam que os canais sejam secos, para se obter uma melhor leitura. 
MOURA et al. $^{70}$, em 1990, utilizando dois localizadores apicais eletrônicos, o SONO EXPLORER MARK III e o ENDOMETER, fizeram uma comparação clínica com o método radiográfico de odontometria proposta por PAIVA e ANTONIAZZI ${ }^{79}$, e para tanto, selecionaram setenta e um dentes, sendo vinte e oito (36 canais) portadores de polpa viva e quarenta e três (55 canais) de polpa mortificada, perfazendo um total de 91 canais. Tanto para as polpas vivas como para as mortificadas o ENDOMETER mostrou ser melhor para aferir medições maior ou igual a 1,0 mm aquém do ápice radicular quando comparado ao SONO-EXPLORER. Apesar disto, concluem os autores que ambos os aparelhos revelam-se eficientes na determinação do comprimento dos canais radiculares.

Com o objetivo de testar clinicamente, através de medição direta, GAVINI; AUN; BARBERINI ${ }^{40}$, em 1990, utilizaram o localizador apical eletrônico SONO-EXPLORER MARK III, e realizaram as medidas em 40 dentes uniradiculados, portadores de polpa necrótica e com indicação prévia de extração. Após a realização da odontometria pelo método audiométrico, os dentes foram avulsionados e as medidas fornecidas pelo aparelho foram comparadas com as encontradas pela mensuração direta, observando-se que houve coincidência dos valores encontrados em $87,5 \%$ dos casos. Também constataram que nos casos em que não houve coincidência, as medidas encontradas pelo localizador apical sempre foram menores que as reais.

McDONALD; HOVLAND ${ }^{67}$, em 1990 realizaram um estudo relacionando a constrição apical ao ápice anatômico na utilização do ENDOCATER. Utilizaram neste experimento 76 canais de 47 dentes previamente indicados para extração. Os dentes foram preparados após terem sido anestesiados e isolados. Uma 
lima foi introduzida no canal e após realizar a leitura com o ENDOCATER, foram fixadas com resina autopolimerizável e os dentes extraídos em seguida. Os dentes foram cortados no sentido vestíbulo-lingual e o ápice anatômico e a constrição apical analisados através de um microscópio ocular. O ENDOCATER foi preciso na localização a $\quad 0,5 \mathrm{~mm}$ da constrição apical em $93,4 \%$ dos casos.

FOUAD et al. ${ }^{37}$, em 1990 avaliaram "in vivo" cinco aparelhos eletrônicos (EXACT-A-PEX， ENDOCATER，NEO-SONO-D，APEX-FINDER, SONO-EXPLORER MARK III), utilizando vinte dentes uniradiculados com indicação prévia de extração. A diferença na porcentagem dos resultados obtidos entre os cinco aparelhos não foi estatisticamente significante, ficando entre 55 a $75 \%$ à precisão dos aparelhos, quando limitado a $0,5 \mathrm{~mm}$ aquém do forame apical.

STEIN; CORCORAN; ZILLICH ${ }^{96}$ em 1990, avaliaram a relação entre os diâmetros da constrição apical e do forame apical, na precisão da leitura do localizador apical NEOSONO-D. Foram utilizados para este estudo 47 dentes de 22 pacientes. Realizado o acesso convencional, uma lima tipo $\mathrm{K}$ foi inserida na posição de $0,5 \mathrm{~mm}$ do forame segundo registro do localizador apical e foi feita a medida do comprimento da lima. Após os dentes serem extraídos a lima foi fixada com resina composta no canal radicular. Foram realizadas secções transversais de $500 \mu \mathrm{m}$ para avaliar as medidas dos diâmetros de constrição apical, do forame apical e da posição da ponta da lima. Os autores concluem que com o aumento do forame, mais distante a lima fica do ápice.

RICARD et al. ${ }^{88}$ em 1991, fizeram uma avaliação clínica da precisão do EVIDENT RCM MARK II, utilizando-se para este estudo 37 dentes humanos com 
extração indicada. Após a extração, a diferença entre a posição do forame apical determinado eletronicamente e sua real localização anatômica foi medida com microscópio binocular. Os resultados apresentaram uma localização precisa em $\pm 0,5$ $\mathrm{mm}$ do forame apical em $86 \%$ dos casos. Os autores ainda afirmam que neste estudo não houve diferença estatística entre os resultados obtidos com polpas vitais e com polpas necróticas.

Em 1991, STEIN et al. ${ }^{97}$, realizaram um estudo para avaliar a precisão do método eletrônico na determinação da constrição apical. Utilizaram para este estudo o aparelho NEOSONO-D, em 47 dentes de 22 pacientes, sendo trinta e nove dentes com vitalidade pulpar e oito dentes não vitais. Concluíram os autores que em 44 casos (94\%) a lima não foi além do forame apical. As medidas determinadas pelo NEOSONO-D na constrição apical $(0,763 \mathrm{~mm}$ aquém do forame apical) foram de $68 \%$ dos casos estudados.

KELLER; BROWN; NEWTON ${ }^{55}$, em 1991 avaliaram clinicamente a precisão do ENDOCATER na determinação da localização da constrição apical. Foram avaliados 69 dentes com 99 canais em 9 pacientes, sendo 30 dentes anteriores e 39 posteriores. A análise dos resultados demonstrou que o ENDOCATER localizou a constrição apical com precisão em 33 canais ou 34,4\% dos casos; já em 48,7\% as medidas demonstraram estar além do limite CDC e 16,7\% ficaram aquém desse limite. Concluíram os autores que novas pesquisas com localizadores de ápices radiculares serão necessárias antes da substituição da técnica radiográfica.

WU; SHI; HUANG ${ }^{107}$, em 1992 realizaram um estudo clínico e laboratorial com o objetivo de determinar a precisão da medição eletrônica utilizando o 
aparelho SONO-EXPLORER TIPO Y-III, verificando se ocorre alteração na medida com a variação do tamanho do forame apical. Foram utilizados neste experimento 20 dentes uniradiculados com indicação de extração, que após terem sido realizadas as medidas com o aparelho foram removidos e seus comprimentos registrados. No estudo laboratorial 19 canais foram simulados em tubos plásticos de 10,5 mm de comprimento, com diâmetros diferentes em sua parte inferior, reproduzindo a variabilidade das formas dos ápices radiculares. Considerando a escala de mais ou menos $0,5 \mathrm{~mm}$ do ápice anatômico, o aparelho realizou leituras precisas em 77,5\% dos casos estudados, considerando uma escala de mais ou menos $2,0 \mathrm{~mm}$ o aparelho se mostrou preciso em $100 \%$ dos casos estudados. Os autores concluem que o tamanho do forame apical foi um dos mais importantes fatores que influenciaram na medição dos canais radiculares.

Um estudo comparando a precisão dos aparelhos ENDEX, EXACTA-PEX, SONO-EXPLORER MARK III e NEO-SONO-D na presença de fluídos no canal e variando o tamanho do forame apical foi realizado em 1993 por FOUAD; RIVERA; KRELL ${ }^{36}$. Neste estudo os autores utilizaram 60 dentes uniradiculados extraídos e conservados em solução de timol a 1\%,que foram divididos em dois grupos, dependendo do tamanho do forame apical. No grupo A (forame estreito) constituído de 30 dentes nas quais a ponta de uma lima tipo Kerr de calibre $n^{0} 30$ não deveria passar através do forame apical. No grupo B (forame apical amplo) as limas de $\mathrm{n}^{\mathrm{o}} 30$ passavam pelo forame apical de 2,0 a 3,0 $\mathrm{mm}$. Um modelo "in vitro" também foi utilizado, no qual os dentes foram presos em tubos testes com as raízes mergulhadas em ágar a 1\% em solução salina tamponada. Medições eletrônicas foram realizadas com três diferentes fluídos no interior do canal radicular, o Etanol 70\%, Xilocaína 2\% e Hipoclorito de sódio a 2,6\%. No grupo A (forame estreito), todos os aparelhos tiveram 
medidas semelhantes, já no grupo B (forame amplo) houve uma grande variação entre os aparelhos, sendo que o ENDEX, foi o que apresentou os resultados mais precisos em relação aos outros aparelhos testados quando da presença de xílocaina e hipoclorito de sódio e especialmente com o forame amplo.

FRANK; TORABINEJAD ${ }^{38}$, em 1993, estudaram “in vivo" a precisão de medida eletrônica do ENDEX na presença de umidade no interior docanal radicular. Foram utilizados 10 operadores para realizar as medidas de 185 canais radiculares em 99 dentes. As medidas obtidas foram comparadas com medições radiográficas.Os resultados obtidos foram de $89,64 \%$ de precisão em canais úmidos quando o limite foi estipulado em mais ou menos $0,5 \mathrm{~mm}$. Os autores finalizam este estudo afirmando, que o ENDEX têm um local definitivo na realização de terapia endodôntica.

Em 1993, HEMBROUGH; WEINE; PISANO ${ }^{46}$ testaram a eficiência do SONO-EXPLORER MARK III, comparando suas leituras com o método radiográfico em vinte e seis molares superiores previamente indicados para extração. O método radiográfico alcançou $92,3 \%$ de acertos, na raiz distovestibular, contra $69,2 \%$ do método eletrônico. Na raiz palatina, o método radiográfico obteve índices aceitáveis em $84,6 \%$ dos casos, contra 76,9\% do SONO-EXPLORER MARK III. Os autores concluíram que os resultados desfavoráveis em torno das leituras realizadas pelo aparelho, indicam a imprecisão do método da resistência e sua pouca aplicabilidade clínica na localização do forame apical.

Utilizando 33 dentes humanos, MAYEDA et al. ${ }^{65}$ em 1993, realizaram medidas eletrônicas “in vivo" com o ENDEX em dentes com polpas vitais e necróticas. Após a determinação do comprimento, a lima foi cimentada no local, os dentes 
extraídos, e as raízes foram então desgastadas até que a lima e o ápice radicular fossem expostos. A posição da lima foi medida em relação ao forame apical. Os resultados indicaram que todas as medições estavam na escala estreita de $-0,86 \mathrm{~mm}$ para $0,5 \mathrm{~mm}$. Não houve diferença estatística nas medições entre canais com polpas vitais e necróticas.

CHRISTIE; PEIKOFF; HAWRISH ${ }^{20}$, em 1993 fazem uma narrativa histórica desde o surgimento dos aparelhos eletrônicos até os aparelhos atuais de terceira geração, mostrando a evolução técnica dos mesmos. Os autores apresentam cinco casos clínicos em que foi utilizado o ROOT ZX na obtenção do comprimento de trabalho. As medidas foram confirmadas através de tomadas radiográficas e após a obturação dos canais. Os autores concluíram que com a utilização de localizadores apicais eletrônicos de terceira geração (método de freqüência), aumenta a segurança à instrumentação dos canais radiculares, uma vez que permite a qualquer momento realizar uma nova medida. Os autores também afirmam que ao realizar eletronicamente a tomada do comprimento de trabalho, é importante combinar o tamanho do instrumento e o tamanho do canal na constrição apical tão mais próximo quanto possível.

RAMOS; BERNARDINELI ${ }^{87}$ estudaram em 1994, a influência do diâmetro do forame apical na precisão de leitura do modelo de localizador apical APIT. Noventa dentes uniradiculados extraídos de humanos, montados em um meio de ágar salino tamponado a $1 \%$, foram preparados e agrupados segundo a padronização do calibre do forame apical. As medições foram realizadas introduzindo-se a lima até a posição indicada pelo fabricante do aparelho como sendo a $1 \mathrm{~mm}$ do ápice, 
correspondente à localização da agulha na marcação central do visor do aparelho. Obtida essa leitura, o instrumento foi fixado na posição, o dente cortado longitudinalmente e calculado a distância entre a ponta da lima e o forame apical, com auxílio de uma lupa de aumento de 7 vezes. Os resultados indicaram que as leituras em dentes cujo diâmetro do forame variava de $0,32 \mathrm{~mm}$ a $0,52 \mathrm{~mm}$, estabeleceram um comprimento de tamanho a $0,54 \mathrm{~mm}$, em média, do ápice radicular, não havendo diferença estatisticamente significante nos valores obtidos pelas medições dos dois grupos. Os dentes com forames padronizados a $0,72 \mathrm{~mm}$ de diâmetro, indicaram leituras, em média, a 1,61 mm do ápice radicular, sendo estatisticamente significante em relação aos demais grupos. Todos os casos estudados apresentaram leituras variando entre o forame apical e 1,9 $\mathrm{mm}$ aquém.

FELIPPE; SOARES ${ }^{30}$ em 1994 avaliaram "in vitro" 350 dentes e utilizaram um aparelho audiométrico para determinar a localização do forame apical. O experimento foi conduzido em 3 fases: 1- Para determinar a localização do forame apical. 2- para estabelecer a distância da ponta do instrumento ao forame apical no momento do som intermitente; e 3- avaliar a influência do calibre da lima empregada em obter as medições. Em 96,5\% dos casos estudados, a localização do forame apical foi determinada nos limites aceitáveis $(0-0,5 \mathrm{~mm})$. Em 60 dentes, onde as medições foram baseadas no sinal áudio intermitente, um ponto de $1 \mathrm{~mm}$ aquém do forame apical foi localizado. Neste experimento os resultados foram os mesmos utilizando limas de maiores calibres em comparação com limas $n^{0} 15$. Os autores consideraram os resultados promissores e uma avaliação clínica do aparelho será desenvolvida. 
NISHIYAMA et al. ${ }^{73}$, em 1994 avaliaram clinicamente a eficiência do APIT na determinação do comprimento dentário. Sessenta canais radiculares que estavam com indicação para realização de tratamento endodôntico foram utilizados neste estudo. Inicialmente eles foram preenchidos com hipoclorito de sódio a 1\%, para então, proceder-se às medidas com o aparelho. Com o instrumento endodôntico colocado na posição determinada pelo aparelho, procederam-se as tomadas radiográficas pela técnica periapical da bissetriz. Nas imagens radiográficas eram realizadas às medidas das distâncias entre o ápice radicular e a ponta do instrumento com o objetivo de avaliar a precisão do aparelho. Os resultados obtidos mostraram uma eficiência do aparelho, determinando uma confiabilidade em torno de 98,3\%.

Ainda, em 1994, COUTINHO; SIQUEIRA ${ }^{23}$, avaliaram "in vivo" a eficiência do APIT. Para este estudo utilizaram 40 dentes uniradiculados com indicação de extração, sendo que 20 dentes apresentavam vitalidade pulpar e os outros 20 polpa necrosada. Todos os dentes apresentavam raízes completamente formadas, a coroa estava em bom estado de aproveitamento e o forame apical permitia a passagem de um instrumento endodôntico de calibre $\mathrm{n}^{\circ}$ 10. Após a abertura coronária, realizou-se a irrigação dos canais com líquido de Milton, removendo-se então o conteúdo do seu interior. Realizada a medida eletrônica o dente foi extraído, e os resultados obtidos, comparados com o comprimento real do canal. Dentro de um limite de variação de 0 a 0,3 mm aquém do ápice radicular as medidas coincidiram em 100\% dos casos, levando os autores a concluir que o localizador apical APIT é de grande auxílio no tratamento endodôntico. 
PALLARÉS; FAUS ${ }^{80}$ em 1994, realizaram um estudo "in vivo" comparando dois localizadores apicais eletrônicos. Os aparelhos utilizados foram o ODOMETER e o ENDOCATER. Foram realizadas medições eletrônicas em 116 canais de 34 dentes molares que necessitavam ser extraídos por razões periodontais ou protéticas. As medidas foram realizadas antes e após a remoção do conteúdo dos canais radiculares e também após a secagem dos mesmos. Os resultados foram comparados com o comprimento dos dentes após sua extração. Os resultados demostraram que em canais secos os aparelhos obtiveram marcas de mais ou menos $0,5 \mathrm{~mm}$ do forame apical em $89,6 \%$ dos casos estudados para o ENDOCATER, e $84,8 \%$ dos casos para o ODOMETER. Em presença de umidade no interior do canal, o ENDOCATER demonstrou precisão em 88,37\% dos casos, já o ODOMETER apresentou precisão em $79,3 \%$ dos casos.

CHONG; FORD ${ }^{19}$ em 1994, descreveram os localizadores apicais eletrônicos disponíveis no mercado, os princípios do seu uso e as orientações de como e quando usá-los. Os autores afirmam que para assegurar o sucesso no tratamento de canal radicular o Cirurgião Dentista deve determinar o comprimento de trabalho deste canal. Tradicionalmente isto tem sido determinado usando métodos radiográficos, porém a utilização de métodos eletrônicos tem aumentado muito nos últimos anos. Concluem os autores que o uso de localizadores apicais eletrônicos são de suma importância na determinação do comprimento de trabalho. No entanto, o seu uso não pode substituir a radiografia, embora a radiografia sozinha pode ser insuficiente para verificar a localização da constrição apical. O clínico deve combinar o uso do localizador apical com a radiografia para ter uma maior precisão na determinação do comprimento do canal radicular. 
CZERW; FULKERSON; DONELLY²6, em 1994, realizaram um estudo "in vitro" com a finalidade de mostrar a precisão do EXACT-A-PEX e do FORAMATRON IV, utilizando um modelo feito de gelatina misturada com solução salina estéril. A análise dos resultados mostrou $100 \%$ de coincidências entre as medidas obtidas pelos aparelhos eletrônicos comparados com o comprimento real do dente, mostrando que o modelo de teste de gelatina é um método "in vitro" preciso em determinar o comprimento do canal.

SOUSA NETO et al, ${ }^{94}$ em 1995, realizaram uma avaliação clínica do APIT para determinação da odontometria em 170 pacientes tratados, perfazendo um total de 282 canais. A utilização do aparelho foi realizada de acordo com as instruções do fabricante e com o acompanhamento de um de seus representantes que orientou os profissionais no correto uso do mesmo através de vários experimentos preliminares “in vivo". Ao serem realizadas as medições, obteve-se $98,5 \%$ de sucesso na odontometria conseguida com o APIT, quando comparado com o exame radiográfico. O comprimento de trabalho foi considerado como preciso quando a lima estava situada a 1,0 mm aquém do ápice radicular. Concluem os autores que o APITé eficiente, prático e rápido para determinar o comprimento de trabalho, e que a odontometria eletrônica permite diminuir as tomadas radiográficas necessárias para o tratamento endodôntico.

ARORA; GULABIVALA², em 1995 realizaram um estudo "in vivo" com a finalidade de avaliar a precisão de dois localizadores apicais eletrônicos com conteúdos diferentes no interior do canal radicular.Os aparelhos utilizados foram o ENDEX e o RCM MARK II. O comprimento de 61 canais com conteúdos variados (polpa viva, polpa necrosada, pus/exsudato, hipoclorito de sódio e água) foram 
determinados "in vivo". Limas endodônticas foram cimentadas no interior dos canais radiculares e em seguida realizou-se a medição dos comprimentos dos mesmos utilizando-se o ENDEX. Os dentes após serem radiografados foram extraídos e a distância entre a ponta da lima e o forame apical, foi registrada. Os resultados apontam que o ENDEX foi preciso na localização do forame apical em ( $\pm 1 \mathrm{~mm})$ em $94,4 \%$ dos casos com polpa viva, $81,8 \%$ dos casos de necrose pulpar, $100 \%$ dos casos com pus/exsudato, $100 \%$ dos casos com hipoclorito de sódio ou água destilada, resultando em média 93,4\% de precisão dos casos estudados.

TEIXEIRA et al. ${ }^{103}$, em 1995, realizaram uma avaliação clínica de quatro localizadores apicais eletrônicos, o ENDOSONIC, APIT, ENDODONTIC METERS II e o EXACT-A-PEX. Vinte dentes uniradiculados com extrações indicadas apresentando polpa morta com ou sem lesão periapical, foram utilizados neste estudo. As medidas encontradas variaram de 3,0 $\mathrm{mm}$ aquém até 1,0 $\mathrm{mm}$ além do forame apical. O ENDOSONIC, APIT e ENDODONTIC METERS II, apresentaram $40 \%$ de medidas entre 0,5 a 1,0 mm aquém do término do canal radicular. O EXACT-A-PEX alcançou $30 \%$ deste intervalo de medida. Os autores concluem que para serem mais precisos clínicamente, os localizadores apicais eletrônicos avaliados necessitam de ajustes técnicos.

Ainda no mesmo ano, TEIXEIRA; LAGE MARQUES; ANTONIAZZI ${ }^{102}$; realizaram uma avaliação clínica de dois localizadores apicais, utilizando substâncias irrigadoras variáveis, para verificar se ocorria alteração nos aparelhos testados. Os aparelhos utilizados foram o APIT e o ENDOSONIC, na presença de líquido de Dakin, solução de Milton, água oxigenada a 10 volumes e 
associação tergentol-furacin. Dezoito dentes uniradiculados tiveram suas medidas aferidas pelos aparelhos e foram extraídos posteriormente. Os resultados obtidos pelo APIT apontaram medidas coincidentes com o comprimento real dos dentes em $38,8 \%$ dos casos. Já o ENDOSONIC mostrou esta coincidência em 27,7\% dos casos estudados. Para o grupo em que foi utilizado o APIT, as medidas encontradas além do forame apical registraram um índice de $38,9 \%$, e no grupo em que foi utilizado o ENDOSONIC registraram um índice de $50 \%$ dos casos. Os resultados foram idênticos para ambos os aparelhos, com índice de $22,3 \%$, quando consideradas as medidas aquém do forame apical. Dentro das condições estudadas concluíram os autores que as substâncias irrigadoras utilizadas não alteram os resultados das medidas obtidas.

VIEYRA; SALCEDO; GUARDADO ${ }^{105}$ em 1995 realizaram um estudo "in vivo" utilizando 110 dentes permanentes com indicação de tratamento endodontico, sendo 45 dentes anteriores, 45 pré-molares e 20 molares. O objetivo deste trabalho foi comparar o método radiográfico com o método eletrônico na obtenção do comprimento de trabalho. Foi utilizado o FORAMATRON IV, que tem o seu funcionamento baseado no princípio da resistência elétrica. Concluíram os autores que quando se utiliza o sistema elétrico em dentes com ápices abertos e também com instrumentos endodonticos de calibre muito finos $(06,08,10)$ as leituras podem ser falsas. Os canais devem estar secos e os instrumentos endodônticos devem ter tamanhos adequados quando se utilizar este localizador apical.

GOLDBERG $^{42}$, em 1995, avaliou "in vivo", o grau de precisão do ROOT ZX na obtenção da odontometria em comparação com o método radiográfico em 60 canais radiculares de pacientes de ambos os sexos. Os resultados mostraram um 
percentual de $90 \%$ de medições aceitáveis. Não se observou diferença estatística entre as medidas obtidas em dentes com polpa viva e polpa mortificada.

CZERW et al. ${ }^{27}$, em 1995 avaliaram "in vitro" a capacidade em determinar a precisão do forame apical dos aparelhos DIGIPEX III, APEX FINDER, NEOSONO-MC PLUS e ROOT ZX. Foram utilizados 30 dentes anteriores uniradiculados, tendo como parâmetro comparativo uma análise visual direta. No mesmo experimento, foram avaliados os aparelhos com presença ou não de umidade no interior dos canais. Nos canais secos não houve diferença significativa entre as medidas obtidas pelo DIGIPEX III e o ROOT ZX, em relação ao comprimento real do dente. Avaliou-se também a capacidade de mensuração do EXACT-A-PEX na presença de umidade no interior do canal, mostrando não existir diferença estatística entre as medições de canais secos ou úmidos. O ROOT ZX apresentou uma leitura mais confiável em relação aos demais localizadores testados.

PRATTEN; McDONALD ${ }^{83}$ em 1996, realizaram um estudo em dentes de cadáveres humanos comparando a precisão dos métodos eletrônicos e radiográficos para localizar a constrição apical. As radiografias foram avaliadas por cinco examinadores para determinar uma terminação radiográfica de cada canal. Os dentes foram extraídos e examinados histologicamente para determinar o ponto de terminação ideal. A média do valor absoluto dos desvios da constrição apical para o localizador de ápice foi significantemente menor $(\mathrm{p}<0,05)$ do que aquele para o método radiográfico; assim, o método usando o localizador de ápice foi levemente mais confiável. 
LAUPER; LUTZ; BARBAKOW ${ }^{59}$, em 1996, compararam dois localizadores apicais, baseados em princípios diferentes, o APIT (freqüência) e o ODONTOMETER (impedância), quanto à capacidade de localização do forame apical. Um total de vinte e dois dentes (30 canais), apresentando ápices formados e indicados para extração foram utilizados neste estudo. As medidas dos canais radiculares foram obtidas inicialmente com o ODONTOMETER estando os canais sem a presença de umidade e posteriormente utilizando o APIT com os canais úmidos. Em ambas as leituras as limas foram fixadas com resina acrílica que se adaptava a câmara pulpar para posteriormente ser inserida ao ser realizada a extração dentária. Após ser extraído o dente a lima foi novamente colocada no interior do canal radicular. Uma das paredes da raiz do terço apical foi desgastada e a relação da ponta da lima com o forame apical anotada. Os resultados apontaram para o APIT a diferença média entre a ponta da lima e o forame apical $+0,14 \mathrm{~mm}$ para $\pm 0,27 \mathrm{~mm}$ além do forame apical; para o ODONTOMETER 0,36 para \pm 0,71 $\mathrm{mm}$ para além do forame apical.

SHABAHANG; GOON; GLUSKIN ${ }^{93}$, em 1996 avaliaram a capacidade de localização do forame apical utilizando-se do localizador apical ROOT ZX em 26 canais de dentes com vitalidade pulpar e que estavam com extração indicada. Após a extração do elemento dentário foi utilizada microscopia eletrônica para confirmar visualmente a ponta da lima endodôntica em relação ao forame apical. O ROOT ZX localizou exatamente o forame apical em 17 canais $(65,4 \%)$, esteve aquém em um caso $(3,8 \%)$ e esteve além do forame apical em 8 canais $(30,8 \%)$. Quando um erro potencial de $\pm 0,5 \mathrm{~mm}$ do forame é aceitável como uma escala tolerável para aplicação clínica de um localizador eletrônico, este aparelho foi capaz de localizar o forame apical em 25 dentes, perfazendo uma taxa de acerto de 96,2\%. 
FUSS; ASSOOLINE; KAUFMAN ${ }^{39}$ em 1996 compararam "in vitro", a eficácia dos localizadores SONO-EXPLORER MARK III e ENDEX na detecção de perfurações radiculares. Foram utilizados neste estudo 32 dentes humanos extraídos, onde foram realizadas perfurações radiculares no terço médio dos mesmos, após o que, foram incluídos em alginato. Para avaliar a localização das perfurações, foram utilizadas tomadas radiográficas, com ângulos de $0^{\circ}, 25^{\circ}, 90^{\circ}$ e $115^{\circ}$, comparados com localizadores eletrônicos. Quinhentos e doze radiografias foram realizadas para tentar identificar as perfurações radiculares. Dois avaliadores científicos identificaram $45 \%$ das perfurações radiculares quando estas se localizavam na direção buco-lingual. Com os localizadores obteve-se $100 \%$ das medições da extremidade do eletrodo, entre 0,17 e $0,42 \mathrm{~mm}$ aquém do local perfurado.

KOBAYASHI; YOSHIOKA; SUDA ${ }^{56}$, em 1997 desenvolveram um novo aparelho denominado de TRI-AUTO-ZX. O mesmo é formado por um contraangulo com rotação entre 240 e $280 \mathrm{rpm}$, no qual se acoplou um localizador apical eletrônico, o ROOT ZX. Assim durante o preparo do canal radicular é possível monitorar o limite apical. O aparelho também apresenta um sistema de mecanismo autoreverso que permite, quando a lima alcança a constrição apical, ser automaticamente revertida, e também se ocorrer um torque muito elevado à rotação automaticamente é revertida.

OUNSI; HADDAD ${ }^{76}$, em 1998, avaliaram “in vitro" a confiabilidade das mensurações indicadas pelo localizador apical ENDEX em comparação com o método táctil digital e o método radiográfico. Para este estudo foram utilizados 37 dentes uniradiculados extraídos por motivos diversos. Inicialmente foi realizada a 
técnica táctil digital, em que o operador introduzia o instrumento endodôntico até o ponto onde se acreditasse ser o ponto de maior constrição apical. Em seguida foi realizada a localização eletrônica do forame apical. A última fase do experimento consistia em fazer uma tomada radiográfica. As medições dos métodos foram comparadas. O método táctil digital obteve $43,38 \%$ de precisão com relação à detecção do forame apical. O método eletrônico mostrou ser preciso em $84,56 \%$ dos casos e o método radiográfico alcançou 97,06\% de acertos. Acreditam os autores que o alto índice de acerto no método radiográfico esteja relacionado à facilidade da tomada radiográfica "in vitro". Concluem que ambas as técnicas devem ser utilizadas conjuntamente, sendo a técnica eletrônica prioritária no que tange a confiabilidade.

PAGAVINO; PACE; BACCETTI ${ }^{78}$ em 1998, avaliaram "in vivo" o localizador apical ROOT ZX com relação à precisão na localização do forame apical. Foram utilizados para este estudo 29 dentes com vitalidade pulpar. Após os procedimentos de abertura coronária os canais foram irrigados com solução de hipoclorito de sódio a 2,5\%, para em seguida ser removido o excesso do líquido irrigador com aspirador, momento em que foram introduzidas limas endodônticas no canal radicular de dimensões adequadas, variando de 0,8 a 15 no seu calibre. Foram registradas as medidas eletrônicas de acordo com as recomendações do fabricante. As limas foram fixadas com resina fotopolimerisável e em seguida seus cabos foram cortados. Após as extrações dos dentes seus ápices foram observados através de microscopia eletrônica com um aumento de 40x. Os dentes foram classificados em dois grupos. No Grupo A, com 15 dentes, o forame apical parecia estar ao longo eixo do dente. O grupo B, com 14 dentes, o forame apical desviava-se desse eixo. Com um nível de tolerância de $\pm 0,5 \mathrm{~mm}$ a média de precisão clínica do ROOT ZX foi de 82,75\% 
Com um nível de tolerância de $\pm 1,0 \mathrm{~mm}$, foi encontrada uma precisão de $100 \%$ nas amostras. O erro na localização do ápice foi significantemente menor nos casos com um forame apical normal (Grupo A).

FERREIRA; FRÖNER; BERNARDINELI ${ }^{32}$, em 1998 avaliando 88 dentes, totalizando 123 canais, sendo 40 dentes com polpas vivas e 48 com necrose pulpar, destes, 35 dentes com presença de lesão periapical visível radiograficamente e 13 sem lesão periapical visível radiograficamente, de pacientes que seriam submetidos a tratamento endodôntico, realizaram uma comparação clínica da eficiência de dois métodos auxiliares na odontometria: o da tela milimetrada e o APIT 5. A tela milimetrada foi colocada sobre o filme radiográfico durante a tomada da radiografia de diagnóstico. Após o processamento radiográfico obtinha-se uma imagem milimetrada, o que permitiu determinar o comprimento aparente do dente e o comprimento de trabalho inicial. A seguir no mesmo elemento dental foi utilizado o APIT 5 para determinar o comprimento do dente. Os resultados foram concordantes em $76,7 \%$ dos casos quando se tratava de dentes com polpa vital, e naqueles com polpa necrótica os resultados foram concordantes em 83,64\% dos casos. O APIT 5 não foi eficiente na determinação do comprimento radicular somente nos canais obliterados ou com ápices que apresentavam grandes reabsorções. A tela milimetrada apresentou menor eficácia na determinação do comprimento de trabalho devido à própria limitação radiográfica. Concluem os autores que o uso do aparelho eletrônico para localização do forame apical, na clínica, facilita a obtenção da odontometria com diminuição do tempo de trabalho e de tomadas radiográficas. 
ZMENER et al. ${ }^{108}$, em 1999 avaliaram a precisão do TRI-AUTO ZX em determinar e medir a localização de perfurações radiculares preparadas artificialmente. Foram selecionados para este estudo, 40 dentes humanos recém extraídos com canais retos, que após ter sido realizada a abertura coronária e extirpada a polpa, foram instrumentados até uma lima tipo $\mathrm{K} \mathrm{n}^{\circ} 35$. Após a realização de perfurações radiculares em aproximadamente $5 \mathrm{~mm}$ da junção cemento-esmalte com brocas diamantadas, utilizou-se do aparelho e as medidas foram registradas. Os resultados obtidos mostraram ser consistentes na localização das perfurações em 33 dos 40 casos estudados, concluindo os autores que o TRI AUTO ZX constitui um adjunto valioso para localizar e medir perfurações radiculares endodônticas.

MARQUES; MARQUES ${ }^{63}$, em 1999, analisaram a eficiência clínica do JUSTY II, em determinar o comprimento de trabalho na execução de tratamento endodôntico. Foram realizadas medições em 202 dentes, totalizando 407 canais radiculares. Os dentes com indicação de tratamento endodôntico foram isolados, após ter sido realizado o acesso à câmara pulpar, os dentes foram irrigados e a câmara pulpar foi seca com algodão e após certificar que o canal estava úmido a lima foi introduzida até ouvir-se um som intermitente emitido pelo aparelho, ao mesmo tempo em que se observou a marcação no painel de medição entre as áreas amarela e vermelha, indicando que o instrumento estava a aproximadamente $1,0 \mathrm{~mm}$ aquém do ápice radicular. Neste momento ajustava-se o cursor em um ponto referencial do dente e realizava-se uma comprovação radiográfica. O índice de acerto foi de 100\% quando comparado com a radiografia, concluindo os autores que o JUSTY II é eficiente, prático e rápido para determinar a odontometria, reduzindo o número de tomadas radiográficas, porém não substituindo a utilização da radiografia. 
Em 1999, IBARROLA ${ }^{49}$ et al., verificaram se a realização de um préalargamento do canal radicular antes de realizar a odontometria melhorava a eficiência do uso do localizador apical ROOT ZX. Para isto , realizaram um estudo "in vitro" utilizando 32 canais radiculares que foram divididos em dois grupos, sendo que o grupo 1 foi constituído de 16 canais que não foram manipulados antes do uso do ROOT ZX e serviu como grupo controle. No grupo 2, os canais foram pré alargados antes de se realizar as medições. Os resultados destes estudos sugerem que o pré-alargamento dos canais permite a manipulação do comprimento do instrumento endodôntico, para um alcance mais consistente do forame apical, aumentando a eficiência do aparelho.

WEIGER et al. ${ }^{106}$ em 1999, realizaram um estudo "in vitro", comparando dois localizadores apicais com relação à capacidade dos mesmos em localizar precisamente a constrição apical na presença de vários fluídos no interior do canal radicular. Os aparelhos utilizados foram o ROOT ZX e o APIT, realizando a medição em 41 canais radiculares que foram preenchidos com $\mathrm{NaOCl}$ a $1 \%, \mathrm{H}_{2} \mathrm{O}_{2}$ a $3 \%$ e $\mathrm{NaCl}$ a $0,9 \%$. Os dois aparelhos demonstraram na leitura medidora "APEX" que os valores das medições do comprimento de trabalho eletrônico diferiam na presença de $\mathrm{NaOCl}$ ou $\mathrm{H}_{2} \mathrm{O}_{2}$.. Concluiram que sob as condições deste estudo o ROOT ZX proporciona medições mais precisas na presença de $\mathrm{NaOCl}$.

STEFFEN; SPLIETH; BEHR ${ }^{95}$, em 1999, com o objetivo de combinar diretamente a peça de mão CANAL LEADER com o ROOT ZX e o JUSTY II e verificar se o comprimento de trabalho obtido desta maneira era semelhante aos resultados da combinação dos mesmos aparelhos com limas manuais, utilizaram 50 dentes humanos uniradiculados extraídos e que apresentavam ápices completamente 
formados. Foi realizada uma radiografia de controle e a distância do ápice radiográfico com a ponta da lima foi medida e comparado com os resultados da determinação do comprimento medido eletronicamente. Para ambos os aparelhos a diferença entre as medidas obtidas, não foram estatisticamente significante, e sob condições deste estudo o comprimento de trabalho obtido com limas manuais assistidas eletronicamente foi similar àquela obtidas com peça de mão mecânica assistida eletronicamente com o

\section{CANAL LEADER.}

Com o intuito de comparar o ROOT ZX com a medição real do canal radicular, OUNSI; NAAMAN" ${ }^{77}$ em 1999 realizaram um estudo "in vitro" utilizando 39 dentes humanos uniradiculados extraídos, e que apresentavam ápices completamente formados. Foram realizadas as medições e anotadas quando no painel do mostrador digital estava registrando a marca de $0,5 \mathrm{~mm}$ e também quando estava registrando apex. Estas medidas foram comparadas com o comprimento real do canal radicular. O ROOT ZX, mediu na escala de $0,5 \mathrm{~mm}, 84,72 \%$ dos casos. Concluem os autores com os resultados obtidos, que o ROOT $\mathbf{Z X}$ não pode detectar $0,5 \mathrm{~mm}$ para a posição do forame dentro do canal radicular e que deve o mesmo somente ser utilizado para detectar o diâmetro principal no término do canal radicular.

FOUAD; REID ${ }^{35}$, em 2000 realizaram um estudo comparando dentes em que foi realizada a endodontia, tendo sido obtida a odontometria pelo método radiográfico e pelo método eletrônico. Foram utilizados 58 canais de 36 dentes de pacientes da clinica de Endodontia e os estudantes da Graduação participaram deste estudo. Inicialmente os autores realizaram a odontometria de todos canais usando radiografias pré-operatórias e medições eletrônicas. Ficou estipulado que os estudantes 
deveriam determinar o comprimento de trabalho pelo método eletrônico ou radiográfico, distribuído ao acaso. Os estudantes e os instrutores não sabiam qual método foi o escolhido. Após o término dos tratamentos endodonticos, os dentes foram radiografados e as obturações de canais foram consideradas aceitáveis quando estavam no intervalo de 0,0 a 2,0 $\mathrm{mm}$ aquém do ápice radicular. Concluiu-se que os casos em que foram feitas as odontometrias utilizando-se do método eletrônico os resultados foram melhores e também o número de radiografias foi menor no grupo em que foram utilizados localizadores apicais eletrônicos.

SAAD; AL-NAZHAN ${ }^{91}$ em 2000 realizaram um estudo em 14 dentes avaliando uma nova técnica de terapia endodôntica. Este estudo consistia em combinar um localizador apical eletrônico (ROOT ZX) e um sistema de imagem digital (Radivisiografia) na terapia endodôntica. Após examinar uma radiografia préoperatória, foi utilizado o ROOT ZX para determinação do comprimento de trabalho. Após o preparo químico-mecânico deste canal, foi introduzido um cone de guta percha e foi avaliada a sua posição pelo sistema de imagem digital. A obturação do canal foi realizada quando as medições do aparelho eletrônico e o sistema de imagem foram equivalentes. Foi realizada uma imagem digital após a obturação final do canal radicular. Um acompanhamento de 6 a 8 meses após o tratamento revelou uma cicatrização satisfatória, indicando que esta técnica pode ser útil em pacientes comprometidos medicinalmente e que não podem ser expostos a excessiva e repetida radiações durante a terapia endodôntica.

Em 2001, JENKINS et al. ${ }^{52}$, avaliaram a precisão do ROOT ZX na presença de várias soluções irrigadoras utilizadas no tratamento endodontico.Os 
irrigantes testados foram a lidocaína a 2\%, hipoclorito de sódio a 5,25\%, Rc prep, EDTA líquido, peróxido de hidrogênio a 3\% e o Peridex. Foram utilizados 30 dentes uniradiculados neste experimento. As medidas eletrônicas foram executadas com a presença das várias soluções irrigadoras e posteriormente realizou-se a comparação com o comprimento real dos canais radiculares. Não houve diferença estatística significante entre os sete produtos testados. Estes resultados confirmam o conceito, que o ROOT ZX, é um aparelho útil, versátil e preciso, na determinação do comprimento de trabalho com os mais variados tipos de soluções irrigadoras comumente utilizadas na prática endodôntica.

MARTÍNEZ-LOZANO et al. ${ }^{64}$, em 2001, compararam dois métodos radiográficos (filme convencional e radiografia digital), com um localizador eletrônico apical (APIT EM-S3). Para este estudo foram utilizados 28 canais radiculares pertencentes a 20 dentes humanos. Foi feita uma comparação entre a medição do comprimento de trabalho obtido de dois métodos radiológicos e um localizador de ápice. O método eletrônico foi satisfatório em $67,8 \%$ dos casos, já os métodos radiográficos apresentaram uma porcentagem de 50,6\% para o digital e $61,4 \%$ para o convencional. Concluem os autores que nenhuma das técnicas foi totalmente satisfatória em estabelecer o comprimento de trabalho, e também, não houve diferença entre as técnicas investigadas.

FERREIRA; GURGEL FILHO; FRÖNER ${ }^{33}$ em 2001 compararam clinicamente a eficácia dos aparelhos APEX FINDER e ENDOSONIC em relação à técnica radiográfica. Foram avaliados 220 canais radiculares, vitais e necrosados, sendo obtido o comprimento real do dente com os aparelhos eletrônicos e realizada a 
radiografia periapical de odontometria. Os comprimentos obtidos foram concordantes entre os 3 métodos em $67,72 \%$ dos canais com polpa vital, e em 70,0\% dos canais com polpa necrosadas. O ENDOSONIC mostrou-se superior ao APEX FINDER quando comparados com o método radiográfico, sendo que houve concordância entre os métodos em $91,36 \%$ e $69,09 \%$ respectivamente. Os aparelhos não apresentaram bons resultados quando os canais apresentam-se com ápices totalmente atresiados, incompletos ou arrombados. Os autores concluem que os aparelhos eletrônicos são de grande valia para se determinar o comprimento real dos dentes em Endodontia, porém ainda faz-se necessário o uso da radiografia periapical para a confirmação da odontometria em algumas situações clínicas que o uso do aparelho não é indicado.

Em 2001, CUSTÓDIO et al. ${ }^{25}$, realizaram um estudo para comparar a obtenção do CRT (Comprimento Real de Trabalho) através do localizador apical eletrônico TRIAUTO ZX, o qual pode ser utilizado somente com a função de localização apical ou através da função de localização apical associada à instrumentação mecânica do canal radicular. Para isto foram utilizados 32 dentes uniradiculados, nos quais procedeu-se as cirurgias de acesso e irrigação do canal radicular com hipoclorito de sódio a 1\% (5ml por conduto). A amostra foi dividida em três grupos: G1 com determinação do CRT através do localizador apical eletrônico sem a função de instrumentação mecânica, G2 com determinação do CRT através do localizador apical associado à função de instrumentação mecânica e G3 (grupo controle) com CRT observado pela distância da referência incisal até o forame apical com uma lima. O estudo estatístico dos dois métodos frente à análise de variância de Friedman e o teste Wilcoxon com nível de significância de $1 \%$, não indicou diferenças estatisticamente significante entre os dois métodos e o grupo controle. Afirmam os autores que o 
TRIAUTO-ZX utilizado com a função de rotação oferece maior segurança ao profissional devido a reversão do instrumento quando atingido o CRT. A utilização da função movimento não altera a obtenção do CRT.

MOREIRA et al. ${ }^{69}$, em 2001 com o objetivo de estabelecerem a confiabilidade do aparelho BINGO 1020 na determinação do comprimento do dente, selecionaram 90 pacientes que necessitavam de tratamento endodôntico em dentes uniradiculados com diagnóstico de pulpite irreversível. Com a cavidade de acesso, inundada com soro fisiológico, uma lima tipo $\mathrm{K} \mathrm{n}^{\circ} 15$ era introduzida no canal até que se ouvisse o sinal do aparelho indicando que o instrumento atingiu o ápice. Nesse momento era feita uma tomada radiográfica para se observar em que posição a lima se encontrava no canal. Dos noventa casos estudados apenas três não revelaram coincidência entre as informações do aparelho com as da radiografia. Concluem os autores que o aparelho BINGO 1020 se mostrou eficaz na determinação do comprimento do dente para o estabelecimento do comprimento de trabalho e apresentou uma precisão de $96,7 \%$.

BROCHADO et al. $^{14}$, em 2001 compararam a precisão na determinação do comprimento de trabalho propiciada pelos localizadores apicais eletrônicos ROOT ZX, JUSTY II, BINGO 1020. Foram selecionados para o estudo, trinta incisivos centrais superiores, de tamanhos aproximados, com raízes integras e retas, e ápices totalmente formados. Os dentes foram armazenados em solução de formol a $10 \%$ até o momento de sua utilização, quando foram lavados abundantemente com água corrente. Em seguida, foi feita a abertura coronária dos espécimes e sua posterior inclusão em solução de ágar a 1 \% em solução salina de fosfato tamponado, de 
maneira que somente a porção radicular permanecesse submersa em solução. Após realizou-se a determinação do comprimento de trabalho com os referidos aparelhos e os resultados obtidos foram submetidos à análise estatística pelo teste ANOVA. Não houve diferença estatisticamente significante $(p<0,05)$ entre os localizadores.

HECK et al. ${ }^{45}$ em 2001, avaliaram o ENDEX e o ROOT ZX, em 5 variáveis (ENDEX - $1^{\circ}$ sinal e ápice e ROOT ZX a 1,0 mm; 0,5 mm e ápice), propostas pelos fabricantes para comparar os resultados com a medida dos dentes previamente determinados. Utilizaram-se sempre os mesmos 20 incisivos inferiores extraídos de humanos, que para realização das medidas foram fixados numa plataforma de "nylon" com suas raízes mergulhadas numa cuba contendo gelatina preparada com soro fisiológico para simular as condições elétricas dos tecidos periodontais. A comparação entre o comprimento real (controle) e os comprimentos obtidos pelos aparelhos foi realizada por meio de análise de variância - um fator e comparações múltiplas pelo teste de Scheffé (NS 5\%). Não houve diferença significativa entre os grupos. Concluem os autores que a metodologia empregada foi adequada e que os dois aparelhos testados apresentaram comportamento semelhante sem diferenças estatísticas significativas o que sugere que em casos de limitação radiográfica pode-se realizar o tratamento endodôntico orientado somente por este método.

OISHI et al. ${ }^{75}$ em 2002, investigaram a possibilidade de detectar as constrições apicais de canais radiculares usando um localizador apical. Setenta canais de dentes humanos que não foram possíveis de realizar a penetração em toda a sua extensão foram utilizados neste estudo. Baseados em análises radiográficas estes dentes foram divididos em 3 grupos: GRUPO A (constrição nos 3,0 mm do ápice radiográfico - 
23 canais). GRUPO B (não constrito em 3,0 mm do ápice radiográfico - 28 canais). GRUPO C (constrito em mais de 3,0 mm aquém do ápice radiográfico - 19 canais). Foi utilizado o ROOT ZX até onde a lima pudesse alcançar. Houve uma diferença significante entre os grupos A e B. Os autores concluíram que o ROOT ZX não é somente efetivo para detectar a localização do forame apical, mas também é útil para detectar a constrição do canal radicular.

SÁ NETO et al. ${ }^{90}$, em 2002 avaliaram clinicamente a eficácia dos aparelhos APEX FINDER 7005 e ROOT ZX em relação ao método radiográfico. Duzentos canais radiculares, com polpas vitais e necrosadas, foram avaliados utilizando-se de métodos eletrônicos e radiográfico para a determinação da odontometria. Os valores obtidos foram concordantes em $71,25 \%$ dos casos de polpas vitais, e 74,16\% para os casos de polpas necrosadas. O ROOT ZX mostrou-se superior ao APEX FINDER 7005 quando comparados com o parâmetro radiográfico, uma vez que houve concordância de $93 \%$ e $72 \%$ entre os aparelhos e o método radiográfico respectivamente. Os aparelhos não mostraram bons resultados em dentes com grandes reabsorções apicais, ápices incompletos, ou canais obliterados. Concluem os autores que os aparelhos eletrônicos são de grande valia para se determinar o comprimento real dos dentes em Endodontia, porém ainda faz-se necessário o uso de radiografia periapical para a confirmação da odontometria em algumas situações clínicas que o uso do aparelho não é indicado. O ROOT ZX mostrou-se clinicamente superior ao APEX FINDER 7005.

COSTA et al. ${ }^{22}$, em 2002 avaliaram a capacidade de três aparelhos eletrônicos em localizar o forame apical, bem como um ponto situado próximo e aquém 
do forame. Foram empregados 100 dentes humanos. Após o acesso aos canais, os dentes foram medidos pela técnica direta, inserindo-se uma lima no canal até que sua ponta fosse visualizada no forame apical, a distância foi medida com um paquímetro. Em seguida, os dentes foram medidos duas vezes, pelos três localizadores apicais (NEOSONO ULTIMA EZ, FORAMATRON IV e TRI-AUTO ZX). Para a primeira medida, a lima foi introduzida no canal até que seus aparelhos acusassem que a sua ponta chegou ao forame apical (CEF). Para a segunda medida, a lima foi removida do canal no momento em que os aparelhos acusassem que sua ponta chegou à constrição apical ou ao ponto 0,5 , visível no visor (CEC). Para avaliar a capacidade dos aparelhos localizarem o forame foi feita uma comparação das primeiras medidas eletrônicas com as obtidas pelo método direto ( $\mathrm{CEF}$ versus $\mathrm{CD}$ ). As medidas eletrônicas foram consideradas aceitáveis quando coincidentes com as diretas, ou diferentes de $\pm 0,5 \mathrm{~mm}$. Para avaliar a capacidade dos aparelhos localizarem um ponto próximo e aquém do forame, foi feita uma comparação das segundas medidas eletrônicas com as obtidas pelo método direto (CEC versus CD). De acordo com os testes estatísticos aplicados, o TRIAUTO ZX mostrou-se o aparelho mais efetivo na localização do forame apical $(86,3 \%$ de medidas aceitáveis) e alcançou a maior porcentagem de acertos na localização de um ponto situado próximo e aquém do forame $(84,2 \%)$.

LOPES et al. ${ }^{61}$, em 2002 compararam as radiografias convencional e digital (Trophy RVG) após a obtenção do comprimento do canal dos dentes com o localizador apical eletrônico ENDEX. Para o experimento, foram selecionadas dez raízes mésio-vestibulares de molares superiores e um crânio humano para simular as dificuldades anatômicas em uma tomada radiográfica em pacientes. Após a cirurgia de acesso os dentes foram reidratados em soro fisiológico. Os dentes foram fixados em um 
pote de filme fotográfico e suas raízes ficaram imersas em soro fisiológico para simular a impedância gerada entre a mucosa alveolar e os ligamentos periodontais. Foi utilizada uma lima tipo $\mathrm{K} \mathrm{n}^{\mathrm{o}} 15$ para mensurar o comprimento real de trabalho utilizando o ENDEX. No método eletrônico determinou-se o limite apical como sendo a desembocadura do forame. Após a obtenção deste comprimento real de trabalho, os dentes foram introduzidos em um alvéolo do crânio mantido fixo e foi realizada a tomada radiográfica convencional e digital. $\mathrm{Na}$ tomada radiográfica convencional o tempo de exposição foi de 0,5 segundo e na radiografia digital foi de 0,1 segundo. Os resultados mostraram que não houve diferença estatisticamente significante para os métodos testados neste estudo $(\mathrm{p}>0,05)$. Concluem os autores que através da análise dos resultados que as imagens geradas pelas radiografias são semelhantes, e a radiografia digital pode ser um forte candidato a substituir a radiografia convencional, pois o tempo de exposição à radiação é menor e o tempo de aquisição da imagem radiográfica é mais rápido neste tipo de radiografia.

FERRAZ et al. ${ }^{31}$, em 2002 estabeleceram um estudo comparativo "in vivo" para obtenção da odontometria durante o tratamento endodôntico, entre pacientes irradiados e não irradiados, utilizando-se de um aparelho eletrônico localizador apical (AELA/APIT). As medidas foram obtidas entre a ponta do instrumento estabelecido pelo AELA e o vértice apical dos dentes. Os resultados foram analisados e interpretados por meio de radiografias periapicais. Foram utilizados 52 dentes uniradiculados com vitalidade pulpar e ápice totalmente formado de pacientes na faixa etária de 37 a 73 anos, divididos em dois grupos: 1) pacientes submetidos à radioterapia para tratamento de câncer de cabeça e pescoço (26 dentes uniradiculados); 2) pacientes não irradiados (26 dentes uniradiculados). Os resultados obtidos nos dois grupos aproximaram-se 
muito de 1,0 mm aquém do ápice radiográfico, apresentando uma variação de $-1,19 \mathrm{~mm}$ a $-0,82 \mathrm{~mm}$ em $95 \%$ dos casos. Com o método utilizado neste estudo para obtenção da odontometria através do AELA, em nenhum caso, a ponta da lima esteve além do vértice apical radiográfico. O grupo de pacientes irrradiados e o grupo de pacientes não irradiados, tiveram comportamento similares, quanto as distâncias medidas através do AELA . Considerando que a distância média aproximou-se de $-0,8 \mathrm{~mm}$, o AELA mostrou-se um instrumento seguro para obtenção da odontometria em pacientes irradiados.

Em 2002, GIUSTI; LAGE-MARQUES ${ }^{41}$, compararam dois métodos para a obtenção da extensão do canal radicular, primeiramente com o método eletrônico através do localizador apical BINGO 1020 comparando-se à posterior confirmação feita através da radiografia digital direta sistema RVG Trophy. Foram selecionados 21 pacientes totalizando 30 dentes uniradiculados, sendo 12 casos de polpa viva e 18 casos de polpa morta. Os resultados mostraram que $96,67 \%$ das medidas confirmadas pelo sistema de radiografia digital direta permitiram a visualização do halo radiográfico. Constatou-se ainda que as medidas obtidas pelo sistema de radiografia digital direta quando não coincidentes, estavam muito próxima à medida oferecida pelo localizador necessitando de pequenos ajustes. Com este trabalho pode-se verificar a confiabilidade do localizador apical BINGO 1020 na determinação do comprimento de trabalho e ainda demonstrar o quanto o sistema de radiografia digital direta Trophy facilita a obtenção da odontometria. Quando da utilização de um dos métodos gerar dúvidas pode-se obter auxílio do outro método estudado. 
LIMA et al. ${ }^{60}$ em 2002 avaliaram "in vitro" o localizador apical BINGO 1020 quanto à precisão de suas medidas. Foram utilizadas 40 raízes de dentes uniradiculados extraídos, preenchidos com solução de hipoclorito de sódio $1 \%$. Os espécimes foram fixados em gelatina e mensurados com o aparelho BINGO 1020. Como controle foram utilizadas as medidas obtidas através da visualização direta da ponta do instrumento no ápice radicular. O localizador apical BINGO 1020 apresentou aproximadamente $90 \%$ de medidas coincidentes. Concluem os autores que este aparelho apresentou medidas precisas e confiáveis.

ELAYOUTI; WEIGER; LÖST ${ }^{29}$, em 2002, realizaram um estudo “in vitro" para avaliar o ROOT ZX, quando comparado com a técnica radiográfica convencional de odontometria. Foram utilizados 30 pré-molares extraídos por razões diversas, totalizando 43 canais. A determinação do comprimento de trabalho utilizando a técnica radiográfica apontou que em $51 \%$ dos casos a lima estava além do forame apical, apesar da ponta da lima de medição estar localizada de 0 a $2 \mathrm{~mm}$ aquém do ápice radiográfico. Na utilização do $\mathbf{R O O T} \mathbf{Z X}$ este índice diminuiu para 21\%. Concluíram os autores que a odontometria realizada pela técnica radiográfica pode ser melhorada quando complementada com a técnica eletrônica.

Em 2002, POMMER; STAMM; ATTIN ${ }^{82}$, realizaram um estudo "in vivo" comparando o comprimento do canal radicular, utilizando-se do APEX FINDER 7005, quando estes canais se encontravam em estado de necrose, com vitalidade pulpar ou após a desobturação. Foram realizadas as medidas com o APEX FINDER 7005 em 171 canais e também a odontometria pelo método radiográfico. Em 86\% das raízes avaliadas a ponta da lima como indicava o aparelho eletrônico estava localizada a 0,5 
$\mathrm{mm}$ do ponto $1,0 \mathrm{~mm}$ aquém do ápice radiográfico. O APEX FINDER 7005 demonstrou ser mais preciso para determinar a constrição apical em canais vitais $(93,9 \%)$, do que em canais necróticos $(76,6 \%)$. Em canais desobturados a porcentagem foi de 68,4\%. Os autores concluem que o APEX FINDER 7005 é altamente preciso em canais vitais.

BRUNTON; ABDEEN; MACFARLANE ${ }^{15}$, em 2002 realizaram um estudo para detectar se o uso de um localizador eletrônico apical resultava em uma redução da exposição aos Raios-X durante a terapia endodôntica. Cinqüenta caninos e incisivos uniradiculados recém extraídos foram selecionados e divididos ao acaso em dois grupos (A e B) de 25 dentes. O comprimento de trabalho foi determinado radiograficamente com (grupo B) e sem (grupo A) uso adjunto de um localizador de ápice. Após a determinação do comprimento de trabalho, os dentes foram cortados e o comprimento de trabalho atual medido para comparação. Para o grupo A, 14 radiografias foram necessárias para determinar o comprimento de trabalho, em áreas onde o grupo $\mathrm{B}$ não requereu tomada radiográfica; esta diferença foi altamente significante $(\mathrm{p}<0.001)$. O localizador de ápice foi extremamente preciso em localizar o forame apical em todos os dentes testados em 0,5 mm do ápice anatômico e 11 dentes (44\%) no forame apical. 
3 - Proposição 


\section{3 - PROPOSIÇÃO}

Avaliar a capacidade dos aparelhos eletrônicos JUSTY II, ROOT ZX, BINGO 1020, APIT 5 e FORAMATRON IV em determinar o comprimento dos dentes. 
4 - Material e Métodos 


\section{4 - MATERIAL E MÉTODOS}

\section{1 - SELEÇÃO E PREPARO DOS DENTES}

Foram selecionados para este estudo 30 dentes incisivos centrais superiores permanentes de humanos, extraídos por razões diversas, provenientes do arquivo de dente da disciplina de endodontia da Faculdade de Odontologia de BauruUSP. Esses dentes apresentaram tamanhos e formas aproximadas, raízes íntegras, retas e ápices totalmente formados. Os dentes foram armazenados em formol a $10 \%$ até o momento de sua utilização, quando foram lavados abundantemente em água corrente.

Foi feito acesso coronário em todos os dentes, utilizando-se de pontas diamantadas para alta rotação FG 1016 HL $^{*}$, removendo o conteúdo pulpar dos mesmos com limas tipo $\mathrm{K}^{* *}$ de calibre compatível com o do canal radicular.

\section{2 - MODELO EXPERIMENTAL}

Os dentes assim preparados foram numerados de 1 a 30 e colocados em 5 cubas de vidro de $7 \mathrm{~cm}$ de diâmetro por $5 \mathrm{~cm}$ de altura, seis dentes em cada cuba (Figura 2), de tal forma que suas porções radiculares ficassem submersas em solução de ágar a $1 \%$ em solução salina de fosfato tamponado $(8,0 \mathrm{~g}$ de cloreto de sódio; $0,2 \mathrm{~g}$ de

\footnotetext{
* KG Sorensen

** Maillefer Dentsply
} 
cloreto de potássio; $1,15 \mathrm{~g}$ de fosfato dissódico; $0,2 \mathrm{~g}$ de fosfato potássico; 1 litro de água destilada). Esta solução foi refrigerada por 2 horas até a geleificação do ágar. Em seguida os canais radiculares foram preenchidos com hipoclorito de sódio a $1 \%{ }^{* * *}$ até o terço cervical, deixando a câmara pulpar livre de solução irrigadora. O excesso foi removido com bolinhas de algodão. Procedeu-se desta maneira com todos os grupos dentais, exceto o FORAMATRON IV; no qual foi realizado uma irrigação final com água destilada e os canais foram secos com cones de papel antes da realização da leitura eletrônica.

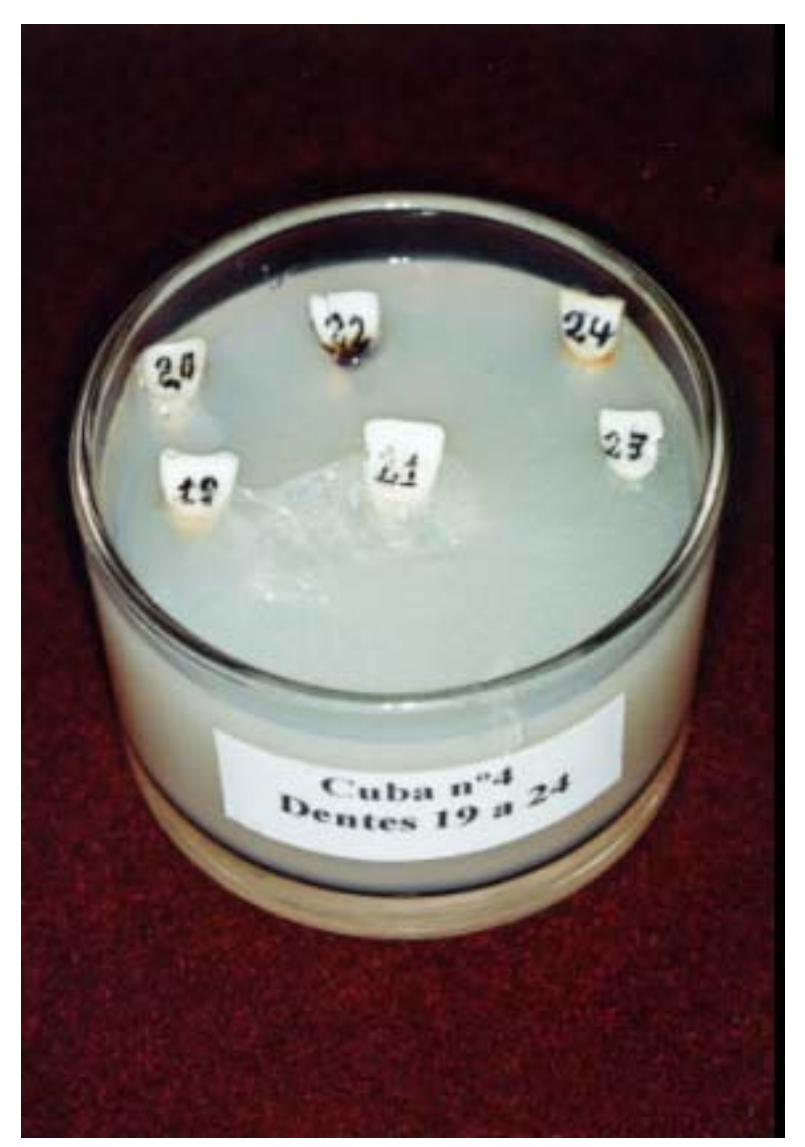

Figura 2- Posição dos dentes na cuba de vidro com a solução de ágar a 1\%.

Para a realização das medições eletrônicas foram utilizados os aparelhos: JUSTY II, ROOT ZX, BINGO 1020, APIT 5 e FORAMATRON IV

*** Solução de Milton 
(Quadro 1, Figura 4). As medições foram realizadas conectando um eletrodo do aparelho em uma lima do tipo $\mathrm{K}$ que melhor se ajustasse ao canal radicular dos dentes em questão. O outro eletrodo do aparelho foi inserido no meio ágar lateralmente ao dente a ser mensurado. A leitura da posição do forame apical foi executada introduzindo-se uma lima compatível com o diâmetro do canal radicular no interior do mesmo e movendo-a lentamente no sentido apical até que registrasse no aparelho 0,5 mm no visor do mesmo (Figura 3). No JUSTY II, correspondia ao marcador no centro da faixa amarela do aparelho; no ROOT ZX, correspondia ao marcador no centro da faixa verde do aparelho; no BINGO 1020, quando o visor mostrasse os retângulos azuis preenchidos na marca 0,5; no APIT 5, quando a agulha do aparelho estivesse na faixa verde entre 1 e apex e no FORAMATRON IV, quando o mostrador digital registrasse 5.

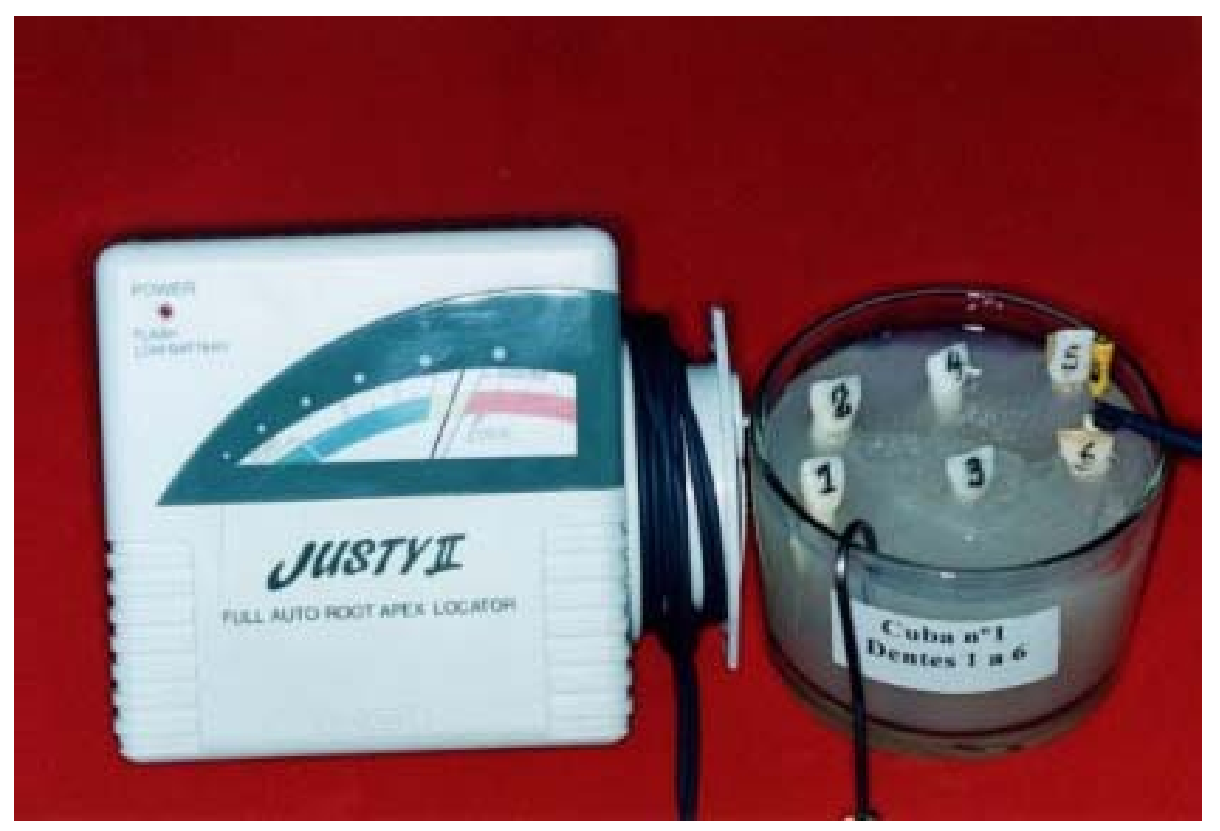

Figura 3- Modo de realizar a leitura com os localizadores apicais eletrônicos. 


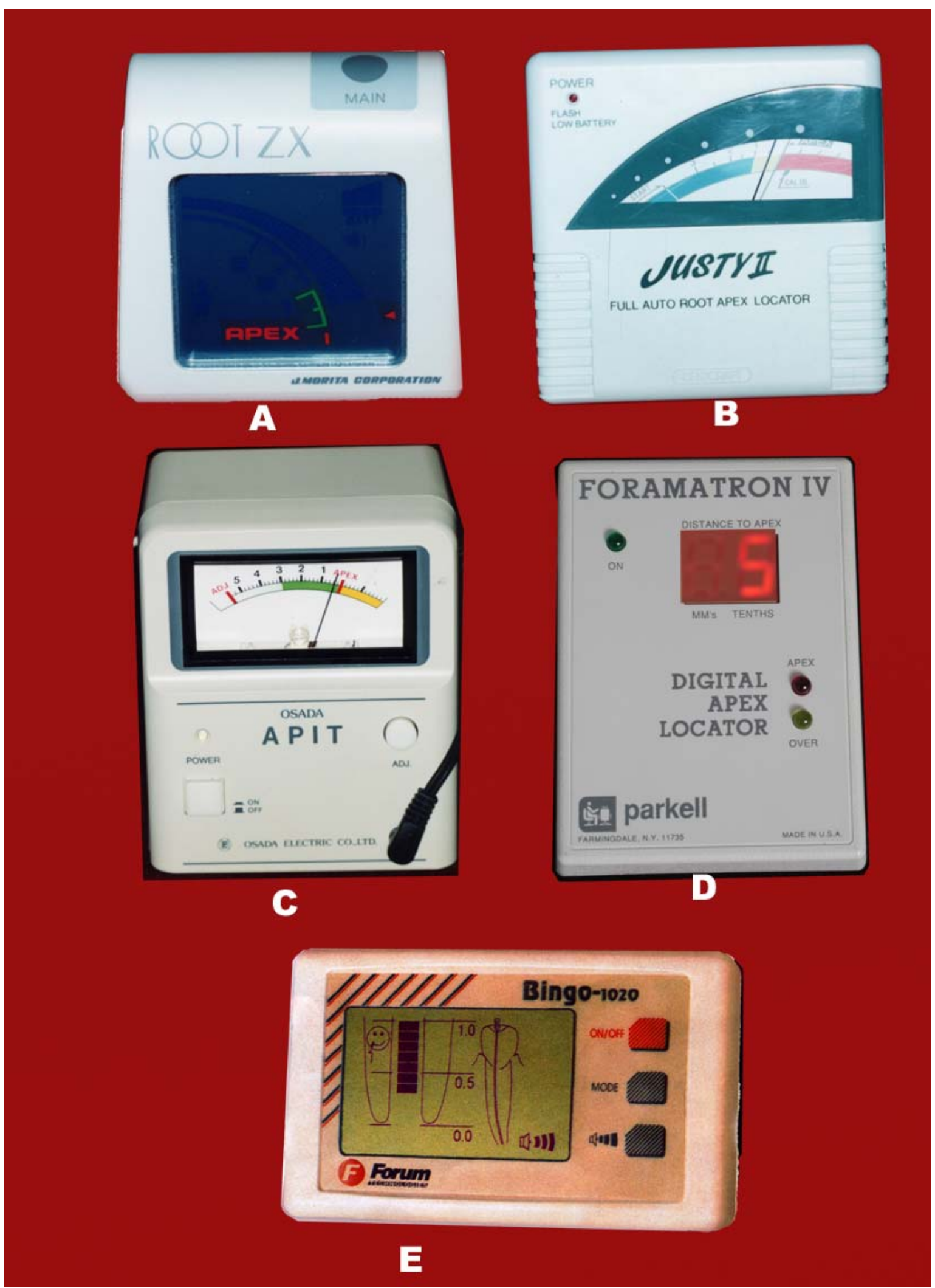

Figura 4 - Aparelhos eletrônicos localizadores apicais utilizados no experimento. 


\begin{tabular}{|l|ll|}
\hline & \multicolumn{1}{|c|}{ APARELHO } & \multicolumn{1}{c|}{ FABRICANTES } \\
\hline A & ROOT ZX & J. Morita - Japão \\
B & JUSTY II & TOEI Yoshida- Japão \\
C & APIT 5 & Osada - Japão \\
D & FORAMATRON IV & Parckell - EUA \\
E & BINGO 1020 & Forum - Israel \\
\hline
\end{tabular}

Quadro 1- Localizadores apicais eletrônicos e seus fabricantes.

Uma vez determinada a leitura no aparelho, um cursor de borracha previamente inserido no instrumento foi deslocado até tocar a borda incisal do dente, neste momento a lima foi desconectada do eletrodo e removida do interior do dente realizando a medição da mesma com um paquímetro*; os valores obtidos foram anotados em uma ficha própria para esta finalidade.

Posteriormente a estas leituras os dentes foram removidos do meio ágar e medidos com um paquímetro do ápice até o bordo incisal e também anotados em fichas próprias. A seguir uma lima de calibre compatível ao diâmetro do canal foi introduzida até que esta pudesse ser vista na saída do forame apical, momento em que o cursor de borracha era ajustado, para realização da medida que também foi anotada. Finalmente, o ponto da saída da lima pelo forame apical, também foi anotado.

Para análise dos dados, utilizou-se de tabelas e gráficos, com parâmetros de média e desvio padrão.

Para comparação entre os cinco aparelhos utilizou-se análise de variância a um critério e o Teste de Tukey para comparações múltiplas.

${ }^{*}$ FWP, Maub, Polland 
Em todos os testes foi adotado nível de significância de 5\%. 
5 - Resultados 


\section{5 - RESULTADOS}

Os valores individuais das medidas obtidas nos diferentes dentes em função do aparelho empregado e a posição do forame estão expressos no Quadro 2.

No Quadro 3 estão expressos os resultados das diferenças entre o comprimento determinado pelos aparelhos e o comprimento do canal determinado pela inserção da lima já descontado $0,5 \mathrm{~mm}$ do comprimento real do canal.

Na Tabela 1 estão os dados da análise de variância a um critério aplicado aos valores do Quadro 2 e 3, tendo como critério as medidas obtidas com os aparelhos em uma variação de $\pm 0,5 \mathrm{~mm}$.

Na Tabela 2 estão os dados referentes ao teste de Tukey na confrontação entre os aparelhos.

A Tabela 3 acolhe o número e porcentagens de acertos e erros considerando a variação de $\pm 0,5 \mathrm{~mm}$ da medida aferida pelos aparelhos.

O Gráfico 1 expressa as porcentagens de acerto na medição dos canais levando-se em conta o aparelho utilizado. 


\begin{tabular}{|c|c|c|c|c|c|c|c|c|}
\hline \multirow{2}{*}{ Dente } & \multirow{2}{*}{$\begin{array}{c}\text { Justy } \\
\text { II }\end{array}$} & \multirow{2}{*}{$\begin{array}{l}\text { Root } \\
\text { ZX }\end{array}$} & \multirow{2}{*}{ Bingo 1020} & \multirow{2}{*}{ Apit 5} & \multirow{2}{*}{ Foramatron IV } & \multicolumn{2}{|c|}{$\begin{array}{c}\text { Comprimento do } \\
\text { dente }\end{array}$} & \multirow{2}{*}{$\begin{array}{l}\text { Posição do } \\
\text { forame }\end{array}$} \\
\hline & & & & & & Lima & Paquímetro & \\
\hline 1 & 21,7 & 22,0 & 22,5 & 22,4 & 22,2 & 22,5 & 22,8 & MV \\
\hline 2 & 25,8 & 26,0 & 26,1 & 26,6 & 25,4 & 26,7 & 27,2 & DV \\
\hline 3 & 22,4 & 22,3 & 22,2 & 22,5 & 22,2 & 22,9 & 23,3 & $\mathrm{P}$ \\
\hline 4 & 19,6 & 19,9 & 20,0 & 19,5 & 19,8 & 20,4 & 21,0 & MV \\
\hline 5 & 22,3 & 22,2 & 22,1 & 21,4 & 22,1 & 23,0 & 24,1 & DV \\
\hline 6 & 24,4 & 24,6 & 24,7 & 24,2 & 26,0 & 25,3 & 26,8 & DV \\
\hline 7 & 22,6 & 23,3 & 22,7 & 22,9 & 22,4 & 23,5 & 24,0 & MV \\
\hline 8 & 19,2 & 19,5 & 19,2 & 19,0 & 19,3 & 19,7 & 20,1 & MV \\
\hline 9 & 24,6 & 25,5 & 25,4 & 24,9 & 24,7 & 25,6 & 26,1 & $\mathrm{D}$ \\
\hline 10 & 21,2 & 21,3 & 21,2 & 21,1 & 21,2 & 21,8 & 22,3 & $\mathrm{D}$ \\
\hline 11 & 20,7 & 21,2 & 21,5 & 21,9 & 21,8 & 21,5 & 22,4 & $\mathrm{~V}$ \\
\hline 12 & 20,3 & 20,3 & 20,7 & 21,5 & 18,5 & 21,1 & 21,8 & MV \\
\hline 13 & 20,5 & 20,8 & 20,9 & 21,5 & 20,1 & 21,2 & 21,9 & DV \\
\hline 14 & 20,5 & 20,7 & 20,7 & 20,8 & 20,2 & 21,0 & 21,4 & DV \\
\hline 15 & 20,5 & 19,6 & 20,3 & 20,3 & 20,0 & 20,5 & 20,5 & A \\
\hline 16 & 20,5 & 20,7 & 20,6 & 20,6 & 19,3 & 21,0 & 21,0 & A \\
\hline 17 & 21,7 & 22,0 & 21,9 & 22,1 & 22,3 & 22,2 & 22,6 & $\mathrm{D}$ \\
\hline 18 & 22,5 & 22,4 & 22,3 & 22,3 & 20,2 & 23,0 & 24,0 & DV \\
\hline 19 & 20,2 & 20,5 & 20,3 & 20,6 & 19,0 & 21,0 & 22,2 & DV \\
\hline 20 & 21,2 & 21,0 & 21,5 & 21,4 & 21,4 & 21,7 & 22,1 & $\mathrm{P}$ \\
\hline 21 & 24,5 & 24,9 & 25,0 & 24,9 & 24,3 & 25,5 & 26,5 & MV \\
\hline 22 & 24,8 & 25,6 & 25,7 & 25,5 & 25,6 & 26,2 & 26,4 & $\mathrm{P}$ \\
\hline 23 & 20,4 & 20,6 & 20,5 & 21,7 & 18,6 & 21,0 & 21,2 & A \\
\hline 24 & 20,9 & 20,5 & 20,9 & 20,2 & 20,5 & 21,4 & 21,8 & DV \\
\hline 25 & 21,8 & 21,8 & 22,1 & 21,7 & 21,0 & 22,3 & 22,8 & $\mathrm{M}$ \\
\hline 26 & 20,5 & 21,0 & 21,0 & 20,0 & 19,4 & 21,5 & 22,2 & MV \\
\hline 27 & 23,0 & 23,7 & 23,1 & 23,6 & 24,2 & 23,8 & 24,2 & $\mathrm{D}$ \\
\hline 28 & 21,6 & 21,2 & 21,2 & 21,5 & 21,1 & 21,7 & 22,7 & $\mathrm{P}$ \\
\hline 29 & 21,3 & 21,5 & 21,6 & 21,7 & 20,8 & 21,9 & 22,0 & A \\
\hline 30 & 23,4 & 23,8 & 23,8 & 23,6 & 22,5 & 24,0 & 24,3 & $\mathrm{P}$ \\
\hline
\end{tabular}

Quadro 2 - Valores individuais (em mm) para todas as medidas executadas. Na última coluna, o local da saída do forame apical. 


\begin{tabular}{|cccccc|}
\hline Dente & Just yI & Root ZX & Bingo 1020 & Apit5 & Foramatron IV \\
\hline $\mathbf{1}$ & $-0,3$ & 0 & $+0,5$ & $+0,4$ & $+0,2$ \\
$\mathbf{2}$ & $-0,4$ & $-0,2$ & $-0,1$ & $+0,4$ & $-0,8$ \\
$\mathbf{3}$ & 0 & $-0,1$ & $-0,2$ & $+0,1$ & $-0,2$ \\
$\mathbf{4}$ & $-0,3$ & 0 & $+0,1$ & $-0,4$ & $-0,1$ \\
$\mathbf{5}$ & $-0,2$ & $-0,3$ & $-0,4$ & $-1,1$ & $-0,4$ \\
$\mathbf{6}$ & $-0,4$ & $-0,2$ & $-0,1$ & $-0,6$ & $+1,2$ \\
$\mathbf{7}$ & $-0,4$ & $+0,3$ & $-0,3$ & $-0,1$ & $-0,6$ \\
$\mathbf{8}$ & 0 & $+0,3$ & 0 & $-0,2$ & $+0,1$ \\
$\mathbf{9}$ & $-0,5$ & $+0,4$ & $+0,3$ & $-0,2$ & $-0,4$ \\
$\mathbf{1 0}$ & $-0,1$ & 0 & $-0,1$ & $-0,2$ & $-0,1$ \\
$\mathbf{1 1}$ & $-0,3$ & $+0,2$ & $+0,5$ & $+0,9$ & $+0,8$ \\
$\mathbf{1 2}$ & $-0,3$ & $-0,3$ & $+0,1$ & $+0,9$ & $-2,1$ \\
$\mathbf{1 3}$ & $-0,2$ & $+0,1$ & $+0,2$ & $+0,8$ & $-0,6$ \\
$\mathbf{1 4}$ & 0 & $+0,2$ & $+0,2$ & $+0,3$ & $-0,3$ \\
$\mathbf{1 5}$ & $+0,5$ & $-0,4$ & $+0,3$ & $+0,3$ & 0 \\
$\mathbf{1 6}$ & 0 & $+0,2$ & $+0,1$ & $+0,1$ & $-1,2$ \\
$\mathbf{1 7}$ & 0 & $+0,3$ & $+0,2$ & $+0,4$ & $+0,6$ \\
$\mathbf{1 8}$ & 0 & $-0,1$ & $-0,2$ & $-0,2$ & $-2,3$ \\
$\mathbf{1 9}$ & $-0,3$ & 0 & $-0,2$ & $+0,1$ & $-1,5$ \\
$\mathbf{2 0}$ & 0 & $-0,2$ & $+0,3$ & $+0,2$ & $+0,2$ \\
$\mathbf{2 1}$ & $-0,5$ & $-0,1$ & 0 & $-0,1$ & $-0,7$ \\
$\mathbf{2 2}$ & $-0,9$ & $-0,1$ & 0 & $-0,2$ & $-0,1$ \\
$\mathbf{2 3}$ & $-0,1$ & $+0,1$ & 0 & $+0,2$ & $-1,9$ \\
$\mathbf{2 4}$ & 0 & $-0,4$ & 0 & $-0,7$ & $-0,4$ \\
$\mathbf{2 5}$ & 0 & 0 & $+0,3$ & $-0,1$ & $-0,8$ \\
$\mathbf{2 6}$ & $-0,5$ & 0 & 0 & $-1,0$ & $-1,6$ \\
$\mathbf{2 7}$ & $-0,3$ & $+0,4$ & $-0,2$ & $+0,3$ & $+0,9$ \\
$\mathbf{2 8}$ & $+0,4$ & 0 & 0 & $+0,3$ & $-0,1$ \\
$\mathbf{2 9}$ & $-0,1$ & $+0,1$ & $+0,2$ & $+0,3$ & $-0,6$ \\
$\mathbf{3 0}$ & $-0,1$ & $+0,3$ & $+0,3$ & $+0,1$ & $-1,0$ \\
\hline & & 0,3 & & \\
$\mathbf{2}$ & & 0,3 & & \\
\hline
\end{tabular}

Quadro 3 - Resultados (em $\mathrm{mm}$ ) de cada aparelho, já descontando $0,5 \mathrm{~mm}$ do comprimento real do canal.

Tabela 1 - Análise de variância a um critério, aplicado aos valores dos quadros 2 e 3.

\begin{tabular}{cccccc}
\hline Grau & Quadrado Médio & Grau & Quadrado Médio & F & P \\
\hline Efeito & Efeito & Erro & Erro & & \\
\hline 4 & 1,6 & 116 & $\mathbf{0 , 1 2}$ & 13,4 & 0
\end{tabular}

- Diferença estatisticamente significante $(\mathrm{P}<0,05)$. 
Tabela 2- Teste de Tukey, para confrontação entre os aparelhos. (as linhas verticais abrangem os aparelhos em que a diferença não foi estatisticamente significante).

\begin{tabular}{l|cc}
\hline \multicolumn{2}{c}{ APARELHO } & MÉDIA \\
\hline ROOT ZX & 0,18 \\
BINGO 1020 & 0,18 \\
JUSTY II & 0,24 \\
APIT 5 & 0,44 \\
FORAMATRON IV & 0,72 \\
\hline
\end{tabular}

Tabela 3 - Valores de acertos e erros (número de dentes e porcentagens), considerando o aparelho utilizado.

\begin{tabular}{lcccc}
\hline \multicolumn{2}{c}{ ACERTOS } & \multicolumn{3}{c}{ ERROS } \\
\hline \multicolumn{1}{c}{ APARELHO } & $\begin{array}{c}\text { Número de } \\
\text { dentes }\end{array}$ & $\%$ & $\begin{array}{c}\text { Número de } \\
\text { Dentes }\end{array}$ & $\%$ \\
\hline JUSTY II & 29 & $96,67 \%$ & 1 & $3,33 \%$ \\
ROOT ZX & 30 & $100 \%$ & 0 & 0 \\
BINGO 1020 & 30 & $100 \%$ & 0 & 0 \\
APIT 5 & 23 & $76,67 \%$ & 7 & $23,33 \%$ \\
FORAMATRON IV & 13 & $43,33 \%$ & 17 & $56,67 \%$ \\
\hline
\end{tabular}




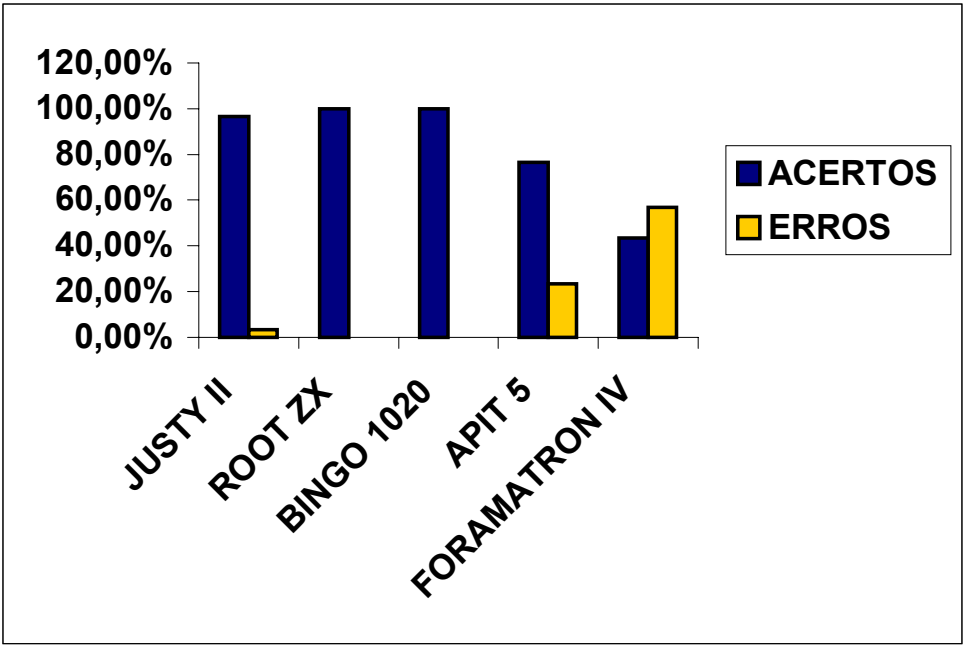

Gráfico 1 - Porcentagem de acertos e erros para cada aparelho 
6 - Discussão 


\section{6 - DISCUSSÃO}

\section{1 - DISCUSSÃO DA METODOLOGIA}

O objetivo principal deste estudo foi fazer uma comparação entre vários aparelhos eletrônicos de localização apical, utilizando para isto de dentes extraídos e de um meio ágar para realização do experimento.

Vários trabalhos com este objetivo já foram desenvolvidos, utilizandose de dentes extraídos. Neste experimento foram utilizados trinta incisivos centrais superiores, extraídos e armazenados em solução de formol a 10\%.

O número de dentes selecionados demonstrou ser suficiente, tendo em vista a homogeneidade dos dentes, assim como os resultados obtidos em testes prévios e observações de outros experimentos desta natureza.

A utilização de incisivos centrais superiores deveu-se ao fato dos mesmos apresentarem uniformidade de raiz e canal radicular. $\mathrm{O}$ armazenamento em formol a $10 \%$ manteve os dentes hidratados e estruturalmente estabilizados, simulando melhor as condições clínicas.

O modelo experimental utilizado neste estudo foi realizado segundo considerações de FOUAD; KRELL ${ }^{34}$. Os autores sugeriram a utilização do meio ágar salino proposto por NAHMIAS; AURELIO; GERSTEIN ${ }^{72}$, que desenvolveram experimentos modificando as concentrações de ágar e promovendo aferições no sentido de eleger a fórmula que mais se aproximava aos valores de condutividade elétrica dos 
tecidos vivos. Concentrações maiores que $2 \%$ proporcionam o posicionamento afastado do ápice do dente a ser mensurado, em relação ao meio, devido o aumento da viscosidade do ágar, promovendo falsas leituras durante a medição. Concentrações abaixo de $1 \%$ determinam a penetração do ágar no interior do canal pelo forame apical, ocasionando leituras mais curtas que o comprimento real do canal.

As cubas de vidro de $7 \mathrm{~cm}$ de diâmetro por $5 \mathrm{~cm}$ de altura que foram utilizadas para acondicionar o ágar, seguiram as indicações de $\operatorname{RAMOS}^{86}, 1993$.

Os dentes foram preenchidos com hipoclorito de sódio a 1\% (Solução de Milton). GROSSMAN ${ }^{44}$ faz menção ao hipoclorito de sódio, em várias concentrações, e seu uso na Endodontia. BERBERT; BRAMANTE; BERNARDINELI ${ }^{7}$ e LASALA ${ }^{58}$ ressaltam a importância do hipoclorito de sódio como coadjuvante nos procedimentos de instrumentação dos canais, indicando a concentração de 1\% (Solução de Milton) como sendo eficiente para tais manobras. Além de sua utilização largamente difundida, a solução mostrou não influenciar na capacidade de leitura dos aparelhos utilizados para medição eletrônica neste estudo, com exceção do FORAMATRON IV que necessitava que o canal estivesse seco ao realizar a medida.

Foram escolhidos cinco aparelhos disponíveis no mercado, sendo o FORAMATRON IV classificado como sendo da primeira geração dos localizadores apicais e o JUSTY II, ROOT ZX, BINGO 1020 e APIT 5 classificados como localizadores de terceira geração.

O APIT 5 é baseado no principio da medição do valor de impedância, relativo a duas freqüências de corrente $(1 \mathrm{Khz}$ e $5 \mathrm{Khz})$. O aparelho funciona a partir da emissão de uma corrente alternada de baixa amperagem $(2 \mu \mathrm{A})$, promovendo leituras dos 
valores de impedância do meio a ser mensurado, quando inserido um eletrodo no interior do canal e outro justaposto à mucosa bucal. A diminuição da impedância a cerca da constrição apical ( há um valor de impedância relativamente constante na junção do tecido pulpar e ligamento periodontal no forame apical), promove a variação do valor relativo às duas freqüências utilizadas, determinando a movimentação para direita da agulha do visor do aparelho. A posição da agulha localizando-se no centro do visor, é interpretada como estando a ponta da lima a $\pm 1 \mathrm{~mm}$ do ápice anatômico. O APIT 5 possui um alarme sonoro, que segundo o fabricante, emite um som intermitente quando o eletrodo da lima posiciona-se a $\pm 1 \mathrm{~mm}$ do ápice e passa a contínuo quando a ponta do instrumento ultrapassa o forame apical (RAMOS,BERNARDINELI 1994) ${ }^{87}$.

O ROOT ZX opera com duas freqüências a partir de uma corrente alternada e calcula a razão da impedância das duas impedâncias relativas a estas freqüências. Possui calibragem automática e pode ser usado como eletrodo limas finas, como a lima tipo $\mathrm{K} \mathrm{n}^{\circ} 8$. O mostrador é digital, e quando o eletrodo da lima posiciona-se na faixa verde do mostrador que fica entre a marca 1 e apex o aparelho emite um som intermitente e neste momento um molar esquemático que se encontra no lado esquerdo do mostrador do aparelho começa a piscar, indicando que a lima se encontra na constrição apical.

O JUSTY II tem o seu funcionamento semelhante ao ROOT ZX, tem duas correntes com duas diferentes freqüências. Ele detecta a parte mais estreita do canal medindo a variação do feedback nos dois sinais.A densidade de corrente é maior na constrição apical, a qual é a parte mais estreita. O mostrador do aparelho é analógico 
e quando o marcador se encontra na faixa amarela o aparelho emite um som intermitente, sendo este o local da constrição apical.

O BINGO 1020, também tem um mecanismo semelhante ao ROOT ZX e ao JUSTY II, e como os aparelhos anteriores seu funcionamento é baseado em duas diferentes freqüências. Tem um mostrador digital e esquematicamente um dente e ao seu lado a numeração que vai de 0.0 até 1.0, sendo que quando o aparelho está em funcionamento e o mostrador digital se encontra em 0.5 , ouve-se um som intermitente emitido pelo aparelho acusando a constrição apical.

O FORAMATRON IV é um aparelho que funciona baseado nos estudos de SUNADA ${ }^{99}$, pelo princípio de resistência elétrica e o canal necessita estar seco no momento de se fazer a medição. É um aparelho com mostrador digital.

Apesar do FORAMATRON IV ser um aparelho de $1^{\text {a }}$ geração dos localizadores apicais, sua inclusão neste experimento se deveu ao fato de que, além de ainda se encontrar no mercado, apenas três trabalhos foram localizados na literatura (CZERW; FULKERSON; DONELLY ${ }^{26}$ em 1994, VIEYRA; SALCEDO; GUARDADO $^{105}$ em 1995 e COSTA et al. ${ }^{22}$ em 2002), sendo que CZERW; FULKERSON; DONELLY ${ }^{26}$ relatam $100 \%$ de precisão do aparelho o que não é comum nos aparelhos de $1^{\mathrm{a}}$ geração onde a média de acerto é bem menor.

Em concordando com NAHMIAS et al. ${ }^{71} 1987$, acredita-se serem os estudos “in vitro" imprescindíveis para obtenção de alguns dados experimentais, porém os resultados não podem ser extrapolados para a clínica, porque embora, desta maneira tenha-se uma condição de simulação clínica, outras variáveis de ordem biológica podem alterar os resultados nas operações "in vivo". 
A avaliação do mecanismo de evolução dos localizadores apicais tem sido descrita e estudada ao longo dos últimos anos, e para isto, os pesquisadores utilizam pesquisas "in vivo", "in vitro", e em alguns casos associando as duas.

Uma das formas de pesquisa mais utilizadas é a comparação entre medidas eletrônicas e tomadas radiográficas. Outra situação é quando se faz a medição eletrônica e posteriormente o dente é extraído e o comprimento real do dente é estimado e comparado com as medidas obtidas eletronicamente.

Pesquisas “in vitro" estão sendo muito utilizadas, possibilitando estudos em dentes extraídos que por sua vez são colocados em recipientes contendo um meio ágar.

A padronização dos dentes e do meio de trabalho diminui a variabilidade entre os grupos estudados, possibilitando uma maior precisão nas leituras dos aparelhos testados dando uma maior confiabilidade nos resultados, muitas vezes não conseguido em estudo "in vivo", devido a grande variedade nas amostras.

Os primeiros estudos realizados "in vitro" na área de medição elétrica do comprimento dos dentes foram realizados por CUSTER $^{24}$ no ano de 1918, e posteriormente originou o desenvolvimento dos localizadores apicais eletrônicos.

Experimentos "in vitro" foram desenvolvidos por HUANG ${ }^{47}, 1987$; RAMOS $^{86}$, 1993; FOUAD; RIVERA; KRELL ${ }^{36}$ 1993; RAMOS \& BERNARDINELI ${ }^{87}$, 1994; CZERW et al. ${ }^{27}$, 1995; KAUFMANN et al. ${ }^{54}$, 1997; STEFEEN et al., 1999; DE MOOR et al. ${ }^{28}$, 1999; WEIGNER et al. ${ }^{106}, 1999$. 
Em 1987, HUANG ${ }^{47}$, apresentou um trabalho em que mostrava que a metodologia na qual era necessário a presença de ligamento periodontal para realizar medições eletrônicas, apesar de não ser inválida, não era correta. A partir de conceitos de física foi possível demonstrar o funcionamento dos localizadores apicais eletrônicos, provando não ser necessário a presença do ligamento periodontal para se fazer medições eletrônicas e com isto tornou-se possível desenvolver análise "in vitro" das medições eletrônicas, utilizando-se de modelos de laboratório NAHMIAS et al. ${ }^{71}$, 1987; CZERW et al. ${ }^{27}, 1994$.

Muitos estudos já foram desenvolvidos sobre a comparação entre dois ou mais aparelhos eletrônicos tomando como base os achados radiográficos. Esta parece ser a maneira mais convencional de estudar os aparelhos eletrônicos. Sabe-se que métodos radiográficos utilizam o ápice radicular e/ou forames apicais como referência. Sabe-se também das dificuldades de visualização desta área, tendo em vista a falta de coincidência do forame apical com o ápice radicular na maioria dos casos.

Estes métodos são de confiabilidade limitada em função das curvaturas e saídas laterais dos forames (MACHADO e PESCE ${ }^{62}$, 1981; PAGAVINO; PACE; BACCETTI, ${ }^{78}$ 1998). Ainda, ocorre uma grande divergência entre os pesquisadores com relação a distância aquém do ápice que deve ser delimitada para a realização do trabalho endodôntico.

Já nos casos em que há indicação da extração dentária, torna-se mais preciso estes estudos, tendo em vista que os instrumentos endodônticos são fixados no interior do canal com resinas ou cimentos, e após ter sido realizada a leitura eletrônica, 
os mesmos são extraídos e seu tamanho real aferido. Nestes casos permitirão uma comparação "in vitro" obtida a partir de uma medida "in vivo".

Estudos realizados por KUTTLER ${ }^{57}$ em 1955, mostrou a grande variedade na forma e local da saída do forame apical, sendo que em menos de $50 \%$ dos casos existe uma coincidência entre a saída do forame com o ápice anatômico; ainda neste estudo o autor conclui que o forame apical possui uma constrição, formada pela junção da parede cementária do canal, sendo esta constrição distante da saída do forame em média 0,507 mm à 0,704 mm. (Figura 1).

GREEN $^{43}$ tem demonstrado em seus estudos da área apical dos dentes que, o forame apical não está localizado no ápice anatômico em um grande número de dentes. A diferença entre os dois pontos pode variar em até $2 \mathrm{~mm}$.

BURCH; HULEN ${ }^{16}$ encontraram uma distância média de $0,59 \mathrm{~mm}$ entre o forame apical e o ápice radicular anatômico em $92,4 \%$ do forame principal estudado.

A escolha do local do forame a ser considerado para as medidas eletrônicas no nosso trabalho foi definido quando o aparelho estava regulado para determinar a constrição apical em $0,5 \mathrm{~mm}$. Considerando, que da constrição para o forame apical há uma variação de 0,5 a 0,7 mm, segundo KUTTLER ${ }^{57}$, estabeleceu-se a extensão do canal levando em consideração o momento em que a lima aparecia no forame diminuindo 0,5 $\mathrm{mm}$. Esse ponto foi escolhido para os testes com os aparelhos

No nosso trabalho optamos em estabelecer o comprimento do dente de duas maneiras: uma por meio do paquímetro, medindo desde a borda incisal até o ápice, 
e a outra inserindo o instrumento no canal até que aparecesse no forame apical o que refletia a leitura dada pelos aparelhos.

Embora alguns autores tenham utilizado o desgaste da ponta da raiz ou a microscopia eletrônica de varredura para estabelecer a distância da ponta do instrumento ao forame apical (RAMOS; BERNARDINELI ${ }^{87}$, 1994, PAGAVINO; PACE; BACCETTI ${ }^{78}$, 1998), nós preferimos basear no recuo do instrumento a partir do forame, uma vez que o desgaste pode fugir do trajeto final do canal dificultando a realização do experimento.

Ainda neste trabalho registramos a localização da saída do forame apical (Quadro1), e podemos observar a grande variedade de localização, o que muitas vezes no exame radiográfico causará um erro de interpretação, o que justifica plenamente a utilização dos localizadores apicais eletrônicos.

Um outro aspecto que foi observado neste estudo, diz respeito a utilização de todos os aparelhos nos mesmos dentes, o que diminui em muito a variabilidade da amostra. Na clínica, a diversidade de anatomia, formatos das raízes, posição dos dentes no arco determinam maiores dificuldades em relação à obtenção de medidas precisas. 


\section{2 - DISCUSSÃO DOS RESULTADOS}

Os resultados deste nosso trabalho permitem ordenar os aparelhos com relação a eficiência. O ROOT ZX juntamente com o BINGO 1020 foram os que melhores resultados demonstraram, seguidos pelo JUSTY II, APIT 5 e finalmente o FORAMATRON IV.(Tabela 3).

Observa-se ainda pela tabela 3 que o ROOT ZX e o BINGO 1020, apresentam uma efetividade de 100\%, enquanto que no JUSTY II e APIT 5 a efetividade foi de $96,67 \%$ e $76,67 \%$ respectivamente, embora a diferença entre os dois não seja estatisticamente significante. (Tabela 2). Estes resultados estão de acordo com os de WEIGER et al. ${ }^{106}$ que comparando os resultados obtidos com o ROOT ZX e o APIT 5 constataram melhores resultados com o ROOT ZX.

Ainda podemos observar na tabela 2 , que não existe diferença estatística entre o ROOT ZX, BINGO 1020 e o JUSTY II. Já o FORAMATRON IV, apresentou uma diferença estatística com relação a todos os outros aparelhos estudados.

Dentre os aparelhos avaliados neste estudo, o ROOT ZX, é um dos que foi mais estudado até o momento. Um dos primeiros estudos sobre este aparelho foram realizados por KOBAYASHI, C.; YOSHIOKA, T.; $\mathrm{SUDA}^{56}$ em 1995, onde apresentou este aparelho com a grande vantagem de medir precisamente o canal até mesmo sob condições elétro condutivas e com princípios de medição elétrica muito diferente dos aparelhos convencionais utilizados. Uma outra vantagem apresentada pelo ROOT ZX é que o mesmo não necessita de calibração no momento do uso. O micro 
processador do aparelho corrige o quociente calculado de forma que a posição da lima e a leitura do medidor estão diretamente relacionados. O ROOT ZX compara uma taxa de diferença entre o sinal de frequência alto $(8 \mathrm{KHz})$ e baixo $(400 \mathrm{~Hz})$. Na prática, a diferença de impedância entre as frequências selecionadas não é afetada pelas propriedades elétricas da solução conforme a sonda condutora progride pelo canal radicular. Devido ao circuito de micro chip construído no instrumento, a leitura digital é produzida somente quando a ponta do instrumento aproxima do forame apical. Unidades baseadas em freqüência como o ROOT ZX são fáceis de manipular porque eles usam limas tipo $\mathrm{K}$ normais em canais úmidos, os quais podem conter um fluído eletro condutivo.

Os resultados por nós encontrados neste estudo com o ROOT ZX estão de acordo com SHABAHANG; GOON; GLUSKIN, ${ }^{93}$ PAGAVINO; PACE;BACETTI ${ }^{78}$, BROCHADO et al. ${ }^{14}$

Os resultados que obtivemos com o JUSTY II estão de acordo com MARQUES; MARQUES ${ }^{63}$ (1999), STEFFEN; SPLIETH; BEHR ${ }^{95} ;(1999)$ e BROCHADO et al. ${ }^{14}(2001)$.

Os resultados do BINGO 1020 foram semelhantes aos obtidos por LIMA, et al. ${ }^{63}$, GIUSTI; LAGE-MARQUES ${ }^{41}$, BROCHADO et al. ${ }^{14}$ e MOREIRA et al. ${ }^{69}$.

Com relação ao desempenho do APIT 5 acreditamos que os resultados não foram tão satisfatórios devido à própria regulagem do aparelho. Quando observadas as medidas no quadro 3 relacionadas ao APIT 5, a grande maioria das mesmas estão além do forame apical, mas de uma forma constante. 
RAMOS; BERNARDINELI ${ }^{87}$, mostram em seu trabalho "in vitro", que no modelo de localizador apical APIT a demarcação correspondente ao limite de 1 mm aquém do forame, encontra-se levemente deslocado para esquerda do visor.

Com o objetivo de padronizar os aparelhos, definimos como local da medida, quando a agulha do mostrador estivesse levemente para direita, o que justifica baseado nos estudos de RAMOS; BERNARDINELI ${ }^{87}$ as medidas terem ultrapassado o forame apical.

Ainda com relação ao APIT 5, os resultados por nós obtidos estão de acordo com os de FERREIRA; FRÖNER; BERNARDINELI ${ }^{32}$ (1998) e em desacordo com NISHIYAMA et al. ${ }^{73}$ (1994); COUTINHO; SIQUEIRA ${ }^{23}$ (1994); SOUZA NETO et al. (1995); ARORA; GUABIVALA² (1995).

O FORAMATRON IV, foi entre os aparelhos testados, aquele que pior resultado apresentou (Tabela 3), inclusive com diferença estatística com relação aos demais aparelhos (Tabela 2).

Acreditamos que os resultados obtidos com o FORAMATRON IV, de apenas $43,33 \%$, tenha ocorrido,devido principalmente a necessidade de se obter um canal seco no momento da realização da medida eletrônica, o que possivelmente não foi sempre conseguido.

Devemos considerar, que os localizadores apicais eletrônicos que exigem ausência de umidade no interior do canal radicular, não deveriam apresentar medidas além do forame apical, uma vez, que o encontro da lima com o fluído do tecido periapical fecharia o circuito elétrico independentemente da constrição apical. Porém 
TEIXEIRA et al. ${ }^{103}$ em 1995 empregaram o EXACT-A-APEX, cujo princípio operacional é o de $\operatorname{SUNADA}^{99}$ (1962) e encontraram 5\% de resultados desse aparelho fora do forame apical. PLANT; NEWMAN ${ }^{81}$ (1976) utilizando-se do SONOEXPLORER, também encontraram resultados semelhantes. Em nosso experimento podemos observar que 7 dos 30 dentes analisados (Quadro 3), quando fizemos uso do FORAMATRON IV, apresentaram medidas além do forame apical.

Dentro de uma margem de $\pm 0,5 \mathrm{~mm}$ nas medidas obtidas pelos aparelhos estudados, apesar do JUSTY II apresentar um índice de acerto de 96,67\% dos casos (Tabela 3), comparado com os outros aparelhos, ele foi o que apresentou as medidas mais aquém em relação ao forame apical, sendo que somente em dois casos e mesmo assim, dentro desta margem de tolerância as medidas se mostraram além do forame apical. (Quadro 3).

Ainda em relação ao JUSTY II, o único caso em que ficou fora da margem estabelecida pelo nosso critério de avaliação dos aparelhos, foi de $-0,9 \mathrm{~mm}$ (Quadro 3), o que nos parece ser bem tolerável, tendo em vista que a grande maioria dos trabalhos sobre aparelhos eletrônicos utiliza uma margem de 1,0 mm.

Observando o quadro 3, podemos perceber que o ROOT ZX foi o aparelho que se apresentou mais consistente nas medidas, ficando constrito suas medidas em $\pm 0,4 \mathrm{~mm}$ somente em quatro casos de 30 ; estes resultados foram seguidos pelo BINGO 1020 que teve dois casos dentro da faixa de $\pm 0,5 \mathrm{~mm}$. 


\section{3 - CONSIDERAÇÕES FINAIS}

Segundo GREEN ${ }^{43}$ (1960), STEIN; CORCORAN; ZILLICH ${ }^{96}$ (1991),

o uso da técnica eletrônica, associada aos métodos radiográficos, pode diminuir o número de radiografias durante a odontometria, diminuindo a radiação ionizante, sendo também um recurso adicional quando a localização do forame e visualização radiográfica do término da raiz são dificultados por detalhes anatômicos. Quando a radiografia inicial é alongada, a utilização de localizadores, reduz o risco de ultrapassar o ápice, reduzindo assim, a lesão aos tecidos periapicais.

A técnica eletrônica pode também ser indicada na odontometria de canais radiculares de gestantes, de pacientes que sofreram tratamentos radioterápicos (FERRAZ et al. $^{31}, 2002$ ), daqueles pacientes que não concordam com múltiplas exposições ao Raio $\mathrm{X}$ ou, ainda, dos que não toleram a colocação de filmes radiográficos na região posterior da boca.

Segundo estudos de NAHMIAS; AURELIO; GERTEIN ${ }^{72}$, 1983; ZMENER et al. ${ }^{108}$, 1999, os localizadores apicais eletrônicos podem localizar perfurações radiculares.

Assim os localizadores apicais eletrônicos podem auxiliar o Cirurgião Dentista não só a detectar o comprimento de trabalho, como também a certificar-se que estamos atuando dentro do canal radicular. 
O importante, no entanto, quando da utilização da técnica eletrônica é que o profissional esteja familiarizado com o aparelho que irá utilizar, para que o mesmo possa obter sucesso em suas medidas para a determinação do comprimento de trabalho.

Porém a radiografia ainda se faz necessário nos tratamentos endodonticos, principalmente no que diz respeito ao diagnóstico, e complementação de tratamento tendo em vista a grande variedade na anatomia dos dentes. 
7 - Conclusões 


\section{7 - CONCLUSÕES}

Com base na observação e análise dos resultados, pode-se concluir

que:

O índice de acerto em determinar o comprimento do dente utilizandose de aparelhos eletrônicos foi semelhante entre o JUSTY II, o ROOT ZX e o BINGO 1020.

O ROOT ZX e o BINGO 1020 foram eficientes em 100\% dos casos e o JUSTY II em $96,67 \%$ dos casos.

O APIT 5 mostrou-se eficiente em 76,67\% na medição do comprimento do dente.

O FORAMATRON IV apresentou somente $43,3 \%$ de índice de acerto nas medições, ficando muito aquém do resultado dos outros aparelhos estudados, sendo estatisticamente diferente dos outros aparelhos.

O APIT 5 e o JUSTY II foram semelhantes estatisticamente. 
Referências Bibliográficas 


\section{REFERÊNCIAS BIBLIOGRÁFICAS}

1 ABBOTT, P.V. Clinical evaluation of an electronic root canal measuring device. Aust. Dent. J., v. 32,n. 1, p. 17-21, 1987.

2 ARORA, R.K.; GULABIVALA, K. An in vivo evaluation of the Endex and RCM Mark II electronic apex locators in root canals with different contents. Oral Surg., v. 79, n. 4, p. 497-503, April 1995.

3 AUN, C.E.; GAVINI, G.; MOURA, A.A.M. Avaliação clínica de um localizador audiométrico na determinação do comprimento dos canais radiculares. Rev. da Ass. Pau. Cirurg. Dent., v.42, n..6, p. 346-8,nov./dez. 1988.

4 AUN, C.E. et al. Avaliação clínica de um localizador apical audiométrico na determinação do comprimento de canais radiculares. Rev. Ass. Paul. Cirurg. Dent., v.42, n.6, p. 349-51, nov./dez. 1988.

5 AURELIO, J.A. ; NAHMIAS, Y. ; GERSTEIN, H. A model for demonstrating an electronic canal length measuring device. J. Endod., v. 9, n. 12, p. 568-9, Dec. 1983.

6 BECKER, G.J. et al. Electronic determination of root canal length. J. Endod., v.6, n.12, p. 876-80, dec. 1980.

7 Berbert, A.; BRAmAnte, C.M.; BERNARDINELI, N. Endodontia Prática. São Paulo, Sarvier,1980. 
8 BERMAN, L.H.; FLEISCHMAN, S.B. Evaluation of the accuracy of the Neosono-D electronic apex locator. J. Endod., v. 10, n. 4, p. 164-6, Apr. 1984.

9 BEST, E. et al. A new method of tooth length determination for endodontic pratice. Dent. Dig., v. 66, p.450-4, 1960.

10 BLANK, L.W.; TENCA, J.I.; PELLEU, G.B. Reliability of electronic measuring devices in endodontic therapy. J.Endod.,v.1, n.4, p. 141-5, Apr. 1975.

11 BRAMANTE, C.M.; BERBERT, A. A critical evaluation of some methods of determining tooth length. Oral Surg., v.37, p.463-73, Mar.1974.

12 BREGMAN, R. C. A mathematical method of determining the length of a tooth for root canal treatment and filling. J. Canad. Dent. Ass., v.16, p.305-6, 1950.

13 BRITTO JR., L.S.; BIRAL, R.R.; VALDRIGHI, L. Estudo comparativo dos métodos eletrônico e radiográfico nas odontometrias. Rev. Paul. Odont. v.11, n.3, p. 2-14, Maio/Jun. 1989.

14 BROCHADO, V.H.D. et al. Avaliação da precisão de localizadores apicais eletrônicos na determinação do comprimento de trabalho. Pesquisa Odontológica Brasileira., v.15, n.3, p.79, Set. 2001.

15 BRUNTON, P.A.; ABDEEN, D.; MAcFARLANE, T. V. The effect of an apex locator on exposure to radiation during endodontic therapy. J. Endod., v.28, n.7, p.524-6, July 2002.

16 BURCH, J.G.; HULEN, S. The relationship of the apical foramen to the anatomical apex of the tooth root. Oral Surg., v.34, p.262-6, Aug. 1972. 
17 BUSCH, L.R. et al. Determination of the accuracy of the Sono-Explorer for establishing endodontic measurement control. J. Endod., v.2,n.10,p.295-7, Oct.1976.

18 CERTOSIMO, F.J.; MILOS, M.F.; WALKER, T. Endodontic working length determination-Where does it end? General Dentistry., p.281-6, May./June 1999.

19 CHONG, B.S.; PITT FORD, T.R. Apex locators in endodontics: which, when and how? Dent. Update, v.21, n.8, p.328-30, Oct. 1994.

20 CHRISTIE, W. H.; PEIKOFF, M. D.; HAWRISH, C. E. Clinical observations on a newly designed electronic apex locator. J. Canad. Dent. Ass., v.59, n.9, p.765-772, Sept. 1993.

21 CHUNN, C.B.; ZARDIACKAS, L.D.; MENKE, R.A. In vivo root canal length determination using the Forameter. J. Endod., v. 7,n.11, p. 515-20, Nov 1981.

22 COSTA, F.L.M. et al. Estudo comparativo da capacidade de 3 localizadores apicais eletrônicos na determinação do comprimento dos dentes. Pesquisa Odontológica Brasileira. v.16, p.64, 2002.

23 COUTINHO, T.F.; SIQUEIRA, N.L. Avaliação qualitativa "in vivo" da eficiência do localizador apical elétrico - Apit. Rev. Bras. Odontol. v.51, n.6, p.50-54, Nov./Dez. 1994.

24 CUSTER, L.E. Exact methods of locating the apical foramen. J.Nat.Dent.Ass., v.5, n.8, p.815-9, Apr. 1918. 
25 CUSTÓDIO, A.F. et al. Análise da obtenção do CRT através do localizador apical Triauto-ZX com/sem rotação. Pesquisa Odontológica Brasileira. v.15, n.3, p.27, Set. 2001 .

26 CZERW, R.J.; FULKERSON, M.S.; DONNELY, J. C. An in vitro test of a simplified model to demonstrate the operation of electronic root canal measuring devices. J. Endod., v.20, n.12, p.605-6, Dec. 1994.

27 CZERW, R.J. et al. In vitro evaluation of the accuracy of several electronic apex locators. J. Endod., v. 21, n. 11, p. 572-5, Nov. 1995.

28 DE MOOR, R.J.G. et al. Accuracy of four electronic apex locators: an in vitro evaluation. Endod. Dent. Traumatol., v.15, n.2, p.77-82, Apr. 1999.

29 ELAYOUTI, A.; WEIGNER, R.; LÖST, C. The ability of Root ZX apex locator to reduce the frequency of overestimated radiographic working length. $\mathbf{J}$. Endod., v.28, n.2, p.116-9, Feb. 2002.

30 FELIPPE, M.C.S.; SOARES, I.J. In vitro evaluation of an audiometric device in locating the apical foramen of teeth. Endod. Dent. Traumatol. v.10, p.220222, 1994.

31 FERRAZ, F.C. et al. O uso do localizador apical endodôntico com pacientes irradiados para o tratamento de câncer de cabeça e pescoço. Pesquisa Odontológica Brasileira. v.16, p.119, 2002.

32 FERREIRA, C.M.; FRÖNER, I.C.; BERNARDINELI, N. Utilização de duas técnicas alternativas para localização do forame apical em endodontia: 
avaliação clínica e radiográfica. Rev. Odontol. Univ. São Paulo, v.12, n.3, p.241-6, Jul./Set. 1998.

33 FERREIRA, C.M.; GURGEL FILHO, E.D.; FRÖNER, I.C. Avaliação da determinação da odontometria utilizando-se métodos radiográfico e eletrônico. Pesquisa Odontológica Brasileira. v.15, n.3, p.137, Set.2001.

34 FOUAD, A.F.; KRELL, K.V. An in vitro comparison of five root canal length measuring instruments. J. Endod, v.15, n.12, p.573-7, Dec.1989.

35 FOUAD, A.F.; REID, L.C. Effect of using electronic apex locators on selected endodontic treatment parameters. J. Endod., v.26, n.6, p.363-7, June 2000.

36 FOUAD, A.F.; RIVERA, E.M.; KRELL, K.V. Accuracy of the Endex with variations in canal irrigants and foramen size. J. Endod., v.19, n.2, p.63-7, Feb.1993.

37 FOUAD, A.F. et al. A clinical evaluation of five electronic root canal length measuring instruments. J. Endod, v.16, n.9, p.446-9, Sept.1990.

38 FRANK, A. L.; TORABINEJAD, M. An in vivo evaluation of endex electronic apex locator. J. Endod., v.19, n.4, p.177-9, Apr.1993.

39 FUSS, Z.; ASSOOLINE, L.S.; KAUFMAN, A.Y. Determination of location of root perforations by electronic apex locators. Oral Surg. Oral Med. Oral Pathol. v.82, n.3, p.324-9, Sep.1996.

40 GAVINI, G.; AUN, C.E.; BARBERINI, A.F. Estudo clínico de um localizador apical audiométrico (Sono-Explorer Mark III) na determinação do 
comprimento de canais radiculares. Rev. Fac. Odont. F. Z. L., v.2, n.1, p. 1118, Jan./Jun. 1990.

41 GIUSTI, E.C.; LAGE-MARQUES, J.L. Análise in vivo da medida eletrônica e radiografia digital direta na determinação da extensão longitudinal do canal. Pesquisa Odontológica Brasileira. v.16, p.127, 2002.

42 GOLDBERG, F. Evaluación clínica del Root ZX en la determinación de la condutometria. Rev. Assoc. Odont. Argentina, v.83, n.1, p.180-82, Jul./Set. 1995.

43 GREEN, D.A stereomicroscopic study of 700 root apices of maxillary and mandibular posterior teeth. Oral Surg., v.13, p.728-40, 1960.

44 GROSSMAN, L.I. Endodontia Prática. 8. ed. Rio de Janeiro, Guanabara Koogan, 1976.

45 HECK, A. R. Análise comparativa de dois aparelhos para odontometria eletrônica. Pesquisa Odontológica Brasileira. v.15, n.3, p.136, Set. 2001.

46 HEMBROUGH, J. H.; WEINE, F. S.; PISANO, J. V. Accuracy of an electronic apex locator: a clinical evaluation in maxillary molars. J. Endod., v.19, n.5, p. 242-5, May 1993.

47 HUANG, L. An experimental study of the principle of electronic root canal measurement. J. Endod., v.13, n. 2, p. 60-4, Feb. 1987. 
48 HÜLSMANN, M.; PIEPER, K. Use of an electronic apex locator in the treatment of teeth with incomplete root formation. Endod. Dent. Traumat., v.5, p.238$41,1989$.

49 IBARROLA, J.L. et al. Effect of preflaring on Root ZX apex locators. J. Endod. v.25, n.9, p.625-6, Sep.1999.

50 INGLE, J. I. Endodontics instruments and instrumentation. Dent. Clin. N. Amer., v.1, p.805-22, Nov. 1957.

51 INOUE, N. An audiometric method for determining the length of root canals. J. Canad. Dent. Ass., v.9, p. 630-6, 1973.

52 JENKINS, J.A. et al. An in vitro evaluation of the accuracy of the Root ZX in the presence of various irrigants. J. Endod., v.27, n.3, p.209-11, Mar. 2001.

53 KAUfMAN, A.V.; HELING, B.; SECHAIEK, M. What apex does the SonoExplorer relly read? Quintessence Int., v.12, p.63-71, Dec. 1979.

54 KAUFMAN, A.V. et al. Reliability of different electronic apex locators to detect root perforations in vitro. Int. Endod. J., v.30, n.6, p.403-7, Nov. 1997.

55 KELLER, M.E.; BROWN Jr. C.E.; NEWTON, C.W. A clinical evaluation of the Endocater - An electronic apex locator. J. Endod., v.17, n.6, p.271-4, June 1991.

56 KOBAYASHI, C.; YOSHIOKA, T.; SUDA, H. A new engine-driven canal preparation system with electronic canal measuring capability. J. Endod., v.23, n.12, p.751-4, Dec. 1997. 
57 KUTTLER, Y. Microscopic investigation of root apexes. J.Amer.dent.Ass., v.50,p. 544-52, May 1955.

58 LASALA, A. Endodoncia. 3. ed. Rio de Janeiro, Guanabara Koogan,1983.

59 LAUPER, R.; LUTZ, F.; BARBAKOW, F. An in vivo comparison of gradient and absolute impedance electronic apex locators. J. Endod., v.22, n.5, p.260-3, May 1996.

60 LIMA, R.A. et al. Avaliação do localizador apical Bingo 1020 frente a utilização de hipoclorito de sódio 1\% como substância irrigante. Pesquisa Odontológica Brasileira. v.16, p.174, 2002.

61 LOPES, R. et al. Análise comparativa in vitro entre os métodos radiográfico convencional e digital utilizando o localizador apical. Pesquisa Odontológica Brasileira. v.16, p.93, 2002.

62 MACHADO, M.E.L.; PESCE, H.F. Estudo da região apical de dentes tratados endodonticamente até o vértice radiográfico da raiz. Rev. Assoc. Paul. Cir. Dent., v.35, n.6, p.534-7, Nov./Dez. 1981.

63 MARQUES, J.H.S.; MARQUES, S.B.S. Avaliação na precisão da odontometria com o Justy II, localizador eletrônico de ápice. Rev. da APCD, v.53, n.4, p.285-8, Jul./Ago. 1999.

64 MARTÍNEZ-LOZANO, M.A., et al. Methodological considerations in the determination of working length. Inter. Endod. Journal. v.34, p.371-376. 2001. 
65 MAYEDA, D.L. et al. In vivo measurement accuracy in vital and necrotic canals with the endex apex locator. J. Endod., v.19, n.11, p.545-8, Nov.1993.

66 McDOnALD, N. J. The electronic determination of working length. Dent. Clin. N. Amer., v.36, n.2, p.293-307, Apr.1992.

67 McDONALD, N.J.; HOVLAND, E.J. An evaluation of the apex locator Endocater. J. Endod., v.16, n.1, p.5-8, Jan.1990.

68 MORAES, S.H. et al. Método eletrônico de determinação do comprimento de trabalho. Rev. Ass. Paul. Cirurg. Dent., v.42, n.6, p.359-60, nov./dez. 1988.

69 MOREIRA, E.J.L. et al. Emprego do localizador apical Bingo na determinação da odontometria. Pesquisa Odontológica Brasileira. v.15, n.3, p.139, Set 2001.

70 MOURA, A.A.M. et al. Avaliação clínica de dois localizadores apicais: Endometer e Sono Explorer Mark III. Rev. Bras. Odont. v.47, n.1, p.19-24, Jan./Fev.1990.

71 NAHMIAS, Y.; AURELIO, J.A.; GERSTEIN, H. An in vitro model for evaluation of electronic root canal length measuring devices. J. Endod., v.13, n.5, p.209-14, May 1987.

72 NAHMIAS, Y.; AURELIO, J.A.; GERSTEIN, H. Expaded use of the electronic canal length measuring devices. J. Endod., v.9,n.8,p.347-9, Aug.1983.

73 NISHIYAMA, C.K. et al.. Avaliação clínica da eficiência de um aparelho eletrônico empregado na determinação da odontometria. Rev. Bras. Odont.v.51, n.6, p.45-8, Nov./Dez. 1994. 
74 O'NEILL, L.J. A clinical evaluation of electronic root canal measurement. Oral Surg., v. 38, n. 3, p.469-73, Sept.1974.

75 OISHI, A. et al. Electronic detection of root canal constrictions. J. Endod., v.28, n.25, p.361-4, May 2002.

76 OUNSI, H.F.; HADDAD, G. In vitro evaluation of reliability of the Endex electronic apex locator. J. Endod., v.24, n.2, p.120-1, Feb. 1998

77 OUNSI, H.F.; NAAMAN, A. In vitro evaluation of the reliability of the Root ZX electronic apex locator. Internacional Endodontic Journal, v.32, p.120-3, 1999.

78 PAGAVINO, G.; PACE, R.; BACCETTI, T. A sem study of in vivo accuracy of the Root ZX electronic apex locator. J. Endod. v.24, n.6, p.438-41, June 1998.

79 PAIVA, J.G.; ANTONIAZZI, J.H. Endodontia: Bases para a prática clínica. 2a Ed. São Paulo: Artes Médicas, 1988. p. 886.

80 PALLARÉS, A.; FAUS, V. An in vivo comparative study of two apex locators. J. Endod. v.20, n.12, p.576-9, Dec.1994.

81 PLANT, J.J.; NEWMAN, R.F. Clinical evaluation of the Sono-Explorer. J.Endod., v.2, n.7, p.215-16, July 1976.

82 POMMER, O.; STAMM, O.; ATTIN, T. Influence of the canal contents on the electrical assisted determination of the length of root canals. J. Endod., v.28, n.2, p.83-5, Feb. 2002. 
83 PRATTEN, D.H.; McDONALD, N.J. Comparison of radiographic and electronic working lengths. J. Endod., v.22, n.4, p.173-6, April 1996.

84 RAMOS, C.A.S. Avaliação in vivo da precisão de leitura de um modelo de localizador apical eletrônico.Bauru, 1998. 168p. Tese (Doutorado). Faculdade de Odontologia de Bauru-Universidade de São Paulo.

85 RAMOS, C.A.S. Avaliação in vivo da precisão de um modelo de localizador apical eletrônico. Pesquisa Odontológica Brasileira., v.15, n.3, p.74, Set. 2001.

86 RAMOS, C.A.S. Influência do diâmetro do forame apical na precisão de leitura de um modelo de localizador apical eletrônico. Bauru. 1993. 117p. Dissertação (Mestrado). Faculdade de Odontologia de Bauru - Universidade de São Paulo.

87 RAMOS, C.A.S.; BERNARDINELI, N. Influência do diâmetro do forame apical na precisão de leitura de um modelo de localizador apical eletrônico. Rev. FOB, v.2, n.3, p. 83-90, Jul./Set. 1994.

88 RICARD et al. Clinical evaluation of the accuracy of the evident RCM Mark II Apex locator. J. Endod., v.17, n.11, p.567-9, Nov. 1991.

89 RIKUKAWA, Y. et al. Clinical evaluation of three types of electric root canal measuring equipments: Endocater, Endodontic Meter and Root Canal Meter. Jpn. J. Conserv. Dent., v.26, n.2, p.602-607, 1983. 
90 SÁ NETO, W.C. et al. Avaliação clínica dos localizadores apicais eletrônicos Root ZX e Apex Finder 7005. Pesquisa Odontológica Brasileira. v.16, p.36, 2002.

91 SAAD, A.Y.; AL-NAZHAN, S. Radiation dose reduction during endodontic therapy: a new technique combining an apex locator (Root ZX) and a digital imaging system (radiovisiography). J. Endod., v.26, n.3, p.144-7, Mar. 2000.

92 SEIDBERG, B.H. et al. Clinical investigation of measuring working lengths of root canals with an electronic device and with digital-tactile sense. J. Amer. Dent. Ass., v.90, p.379-87, Feb. 1975.

93 SHABAHANG, S.; GOON, W.W.Y.; GLUSKIN, A. H. An in vivo evaluation of Root ZX electronic apex locator. J. Endod., v.22, n.11, p.616-8, Nov. 1996.

94 SOUSA NETO, M.D. et al. Avaliação de um aparelho eletrônico para determinação da odontometria (condutometria). Rev. Odontol. Univ. São Paulo, v.9, n.1, p.33-37, Jan./Mar. 1995.

95 STEFFEN, H.; SPLIETH, Ch.; BEHR, K. Comparison of measurements obtained with hand files or the canal leader attached to electronic apex locators: an in vitro study. International Endodontic Journal, v.32, p.103-7, 1999.

96 STEIN, T.J.; CORCORAN, J.F.; ZILLICH, R.M. The influence of the major and minor foramen diameters on apical electronic probe measurements. J. Endod., v.16, n.11, p.520-2, Nov.1990. 
97 STEIN et al. Nonionizing method of locating the apical constriction ( minor foramen) in root canals. Oral Surg., v.71,p.96-9,1991.

98 SUCHDE, R.V.; TALIM, S.T. Electronic ohmmeter. An electronic device for the determination of the root canal length. Oral Surg., v.43, n.1, p.141-9, Jan. 1977.

99 SUNADA, I. - New method for measuring the length of the root canal. J. dent. Res.,41.(2): 375-87, Mar./Apr. 1962.

100 SUZUKI, K. Experimental study on iontophoresis. J. JAP. STOMAT.SOC., v.16, p. 414-17, 1942.

101 TEIXEIRA, L.L. Estudo comparativo de três localizadores apicais eletrônicos, tendo em conta o comprimento externo dos dentes e dos canais radiculares. Tese (Doutorado). Faculdade de Odontologia da Universidade de São Paulo. 1997.

102 TEIXEIRA, L.L.; LAGE MARQUES, J.L.; ANTONIAZZI, J.H. Avaliação clínica de dois localizadores apicais eletrônicos de terceira geração. RPG, v.2, n.4, p.204-209, out/dez. 1995.

103 TEIXEIRA, L.L. et al. Avaliação clínica da efetividade de quatro localizadores apicais eletrônicos. Robrac, v.5, n.15, p.13-16, Ago. 1995.

104 USHIYAMA, J. New principle and method for measuring the root canal length. J. Endod., v.9, n.3, p. 97-104, Mar. 1983. 
105 VIEYRA, J.P.; SALCEDO, M.H.H.; GUARDADO, G.A. Foramatron IV: alternativa para establecer la ubicación de la constricción apical (estudio in vivo). Práctica Odontológica., v.16, n.4, p.5-12, Abr. 1995.

106 WEIGER, R. et al. An in vitro comparison of two modern apex locators. J. Endod., v.25, n.11, p.765-8, Nov. 1999.

107 WU, Y.N.; SHI, J.N.; HUANG, L.Z. Variables affecting electronic root canal measurement. Int. Endod. J., v.25, p.88-92, 1992.

108 ZMENER, O. et al. Detection and measurement of endodontic root perforations using a newly designed apex-locating handpiece. Endod. Dent. Traumatol., v.15, p.182-5, 1999. 
Abstract 


\section{ABSTRACT \\ “IN VITRO" ASSESSMENT OF THE MEASUREMENT OF THE LENGTH OF TEETH WITH FIVE TYPES OF ELECTRONIC APEX LOCATORS}

The determination of the apical level of instrumentation is an extremely important requisite for the success of the endodontic treatment. The most used methods are the radiographic, but the electronic methods have been popular among Endodontists and General Practitioners; consequently, many brands of electronic apex locators were developed and are found in the market.

This study has been developed to make an "in vitro" comparison of the measurement of the length of teeth among the electronic apex locators ROOT ZX, JUSTY II, BINGO 1020, APIT 5 and FORAMATRON IV.

Thirty upper incisors extracted from humans were used, which after the coronary opening were measured in two ways. A file was inserted in the canal until its tip showed in the apical foramen, and it was then removed and measured. The other method was measuring the length of the tooth from the incisal edge to the apex with the help of a caliper rule. The teeth were then mounted on a saline agar medium buffered at $1 \%$.

The electronic measurements were obtained with the tested machines when the display marked 0.5 for ROOT ZX, BINGO 1020 and FORAMATRON IV, 
and for JUSTY II when the hand on the display was in the middle of the yellow band between 1 and the apex, and in APIT 5, when the hand was on the green band between 1 and the apex. These measurements were then compared with those previously obtained.

ROOT ZX and BINGO 1020 were efficient in 100\% of cases, JUSTY II in 96,67\% and APIT 5 76,67\%.

FORAMATRON IV presented a success rate of only $43,33 \%$, with a statistically significant difference to the other machines. 